\title{
آليات التعامل مع ظاهرة زيادة انبعاثات غازات الافيئة بالتطبيق على الحالة المصرية
}

\author{
د. مروة سيبوبة حامد*

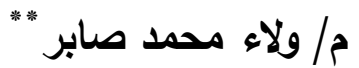

\section{الموجز}

يناقش البحث قضية زيادة انبعاثات غازات الدفيئة وتأثيراتها على البيئة العمرانية، حيث تعد مصر من الدول التي ستتأثر بالتغيرات المناخية وخاصة المناطق الساحلية. تتاول الجزء الأول من البحث عرض لمفهوم وجوانب الظاهرة، ثم تتاول الجزء الثاني من البحث عرض مجموعة من الأسس النظرية والتجارب العالمية التي تبنت المداخل والآليات التخطيطية المختلفة للتعامل مع الظاهرة والتخفيف من زيادة الانبعاثات، والتعامل الفعال مع الآثار المترتبة عليها. ويخلص البحث إلى صياغة إطار مقترح للآليات المتبعة للتعامل مع الظاهرة في مصر واختبار تلك الآليات من خلال دراسة ميدانية. الكلمات الدالة: غازات الدفيئة - التغيرات المناخية - الاحتباس الحراري

\section{Abstract \\ Mechanisms to Deal with the Phenomenon of Increasing Greenhouse Gases Emissions -Applied to the Egyptian Case}

The research discusses the issue of increasing greenhouse gases emissions and their effects on the urban environment, as Egypt is one of the countries that will be affected by climate change, especially coastal areas. The first part of the research dealt with a presentation of the concept and aspects of the phenomenon, then the second part of the research covered a set of theoretical foundations and global experiences that adopted various approaches and planning mechanisms to deal with the phenomenon and reduce emissions, as well as approaches to deal effectively with its implications .The research concludes with formulating a proposed framework for the mechanisms used to deal with the phenomenon in Egypt and testing these mechanisms through a field study.

Key Words: Greenhouse Gases - Climate Change- Global Warming 


\section{مقدمة - مقة}

ترجح أغلب الدراسات أن الأنشطة البشرية المكونة للبيئة العمرانية في المدن هي السبب الرئيسي

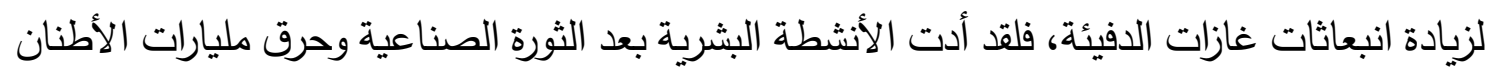

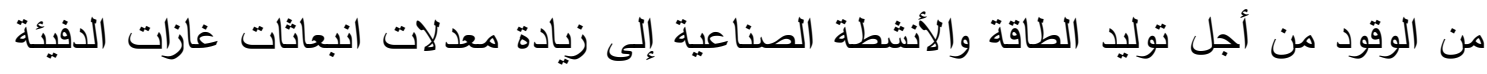

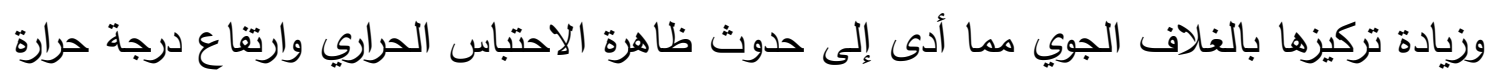

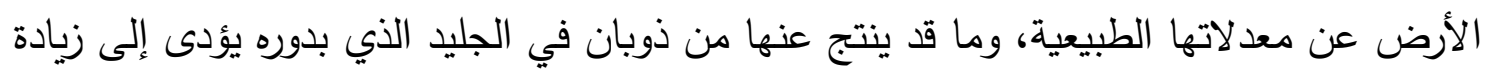

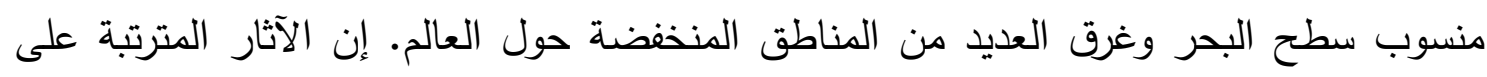

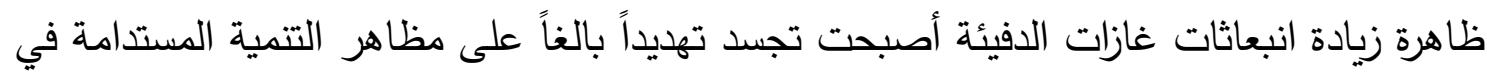

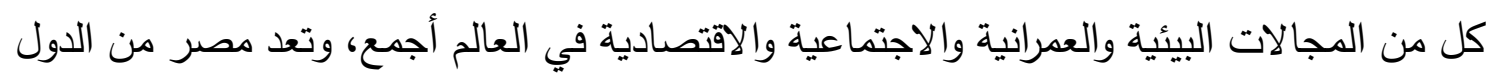

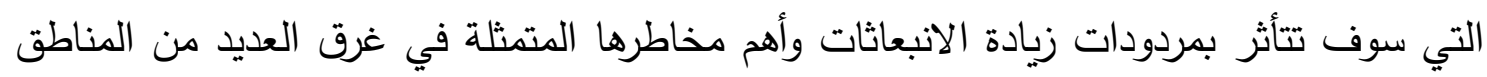

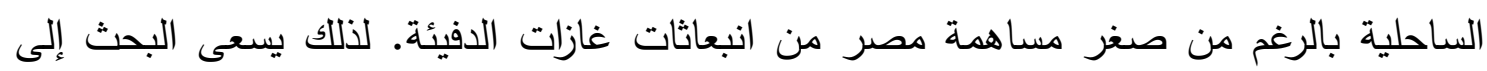

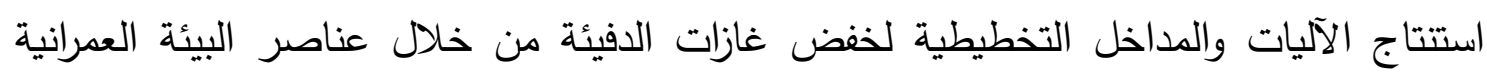

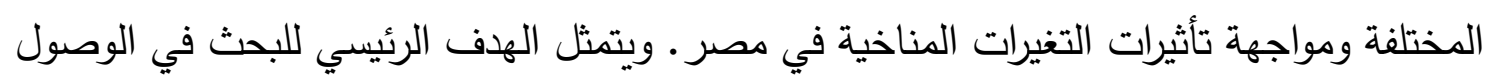

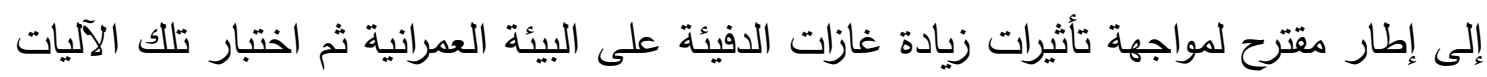
من قبل مجموعة من الخبراء والمتخصصين في المجال في محاولة للوصول إلى مدى إمكانية تطبيق إلى فئيق

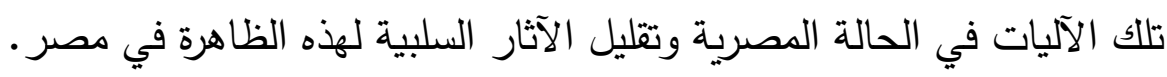


عرض مشكلة زيادة انبعاثات غازات الدفيئة شكل (1) منهجية إجراء الاراسة البحثية

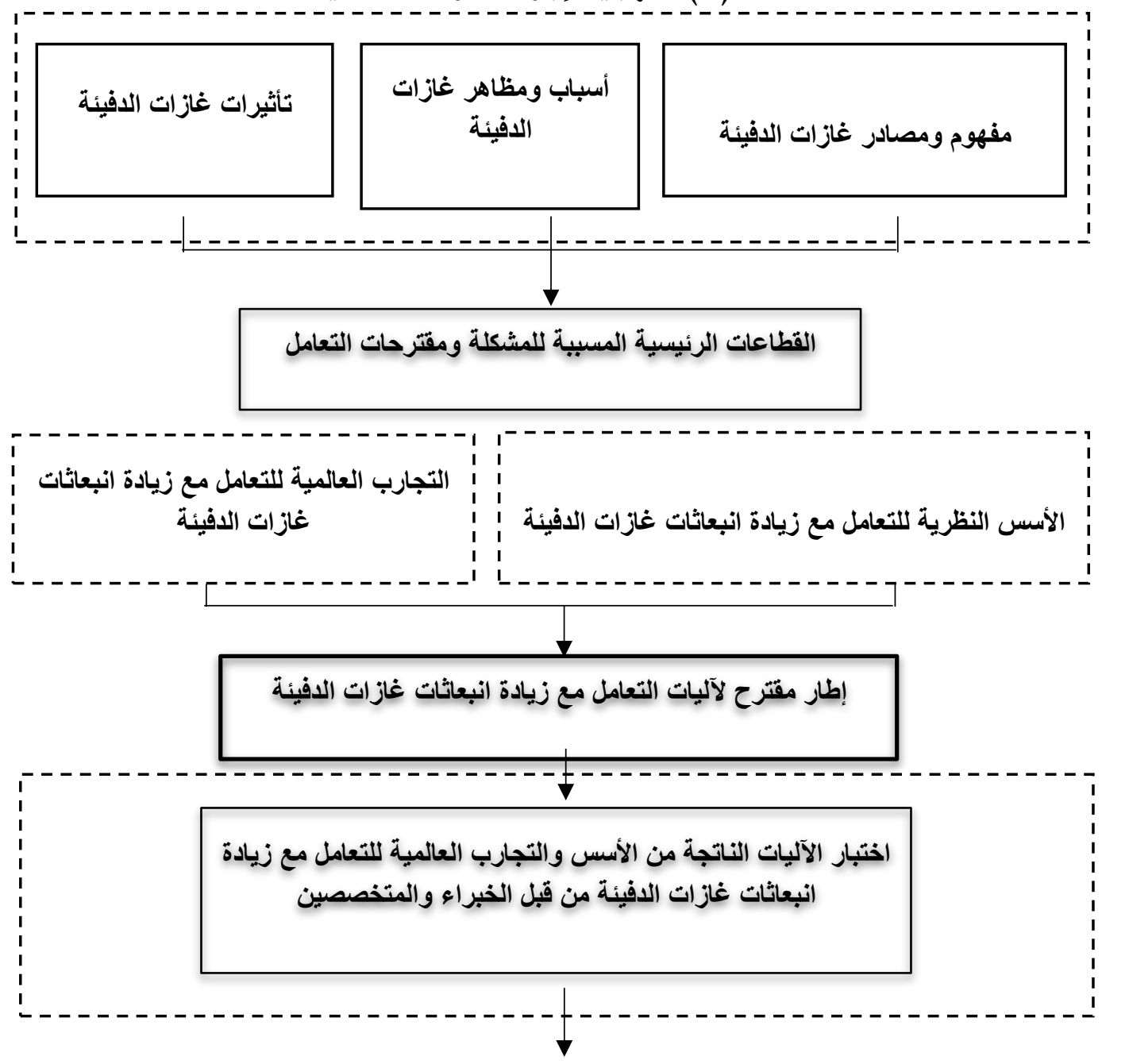

الإطار النهائي لآليات التعامل مع ظاهرة زيادة انبعاثات غازات الدفيئة بالتطبيق على الحالة المصرية 


\section{1 - مفهوم وأهمية غازات الدفيئة}

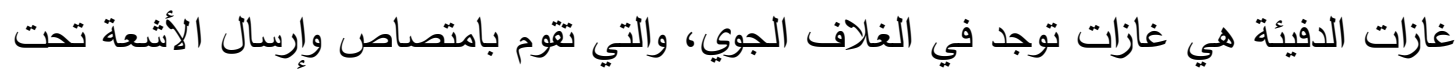

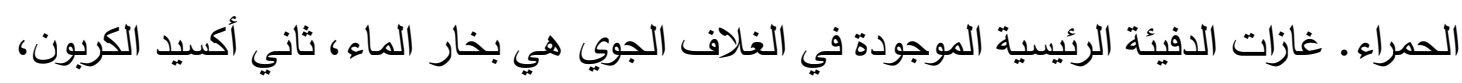

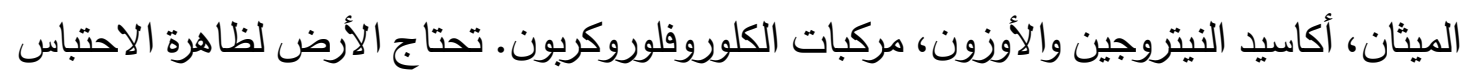

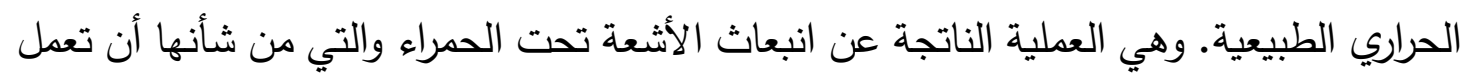

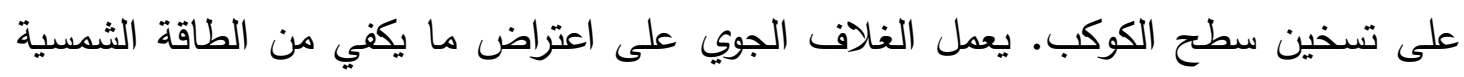

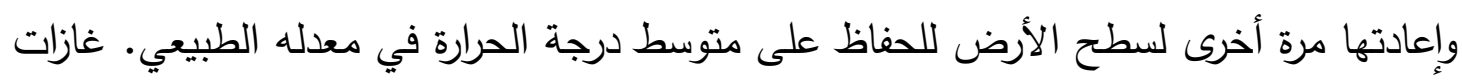

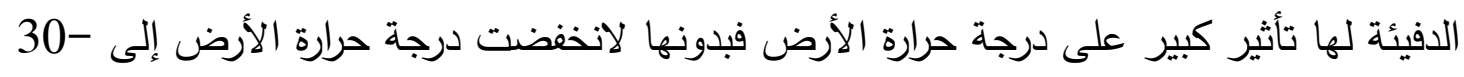
درجة مئوية وأصبحت الأرض مكان لا نستطيع العيش عليه (Casper,2010).

1-1-1 أ1 مصادر انبعاثات غازات الدفيئة

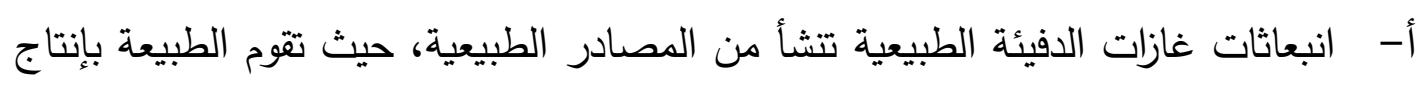

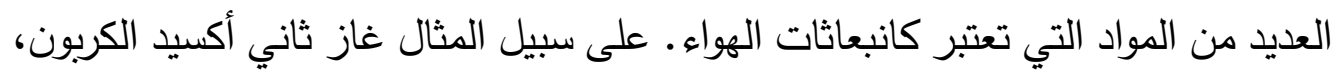

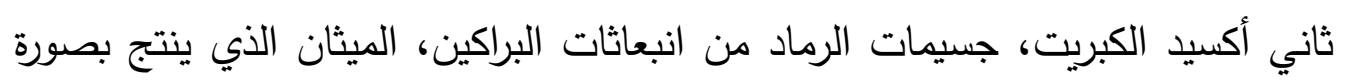
طبيعية بواسطة هضم الطعام عن طريق الحيوانات، غاز الرادون المشع وحرائق الغابات. ومع ذللك، فان هذه المصادر ليست مصدر قلق كبير للمجتمع (Tan,2014).

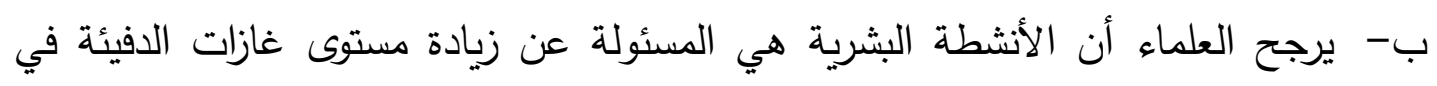

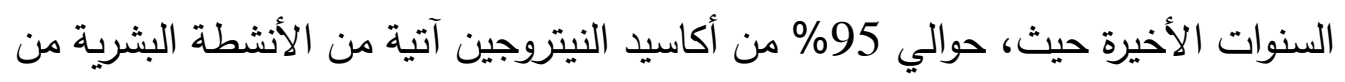

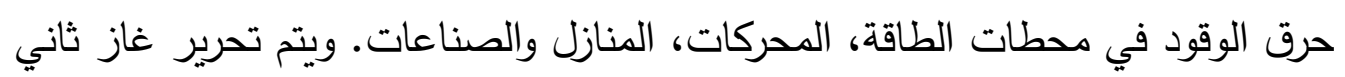
أكسيد الكربون من عملية الاحتراق، ويولد العديد من الملوثات (Tan,2014).

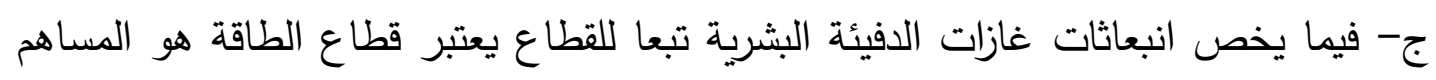

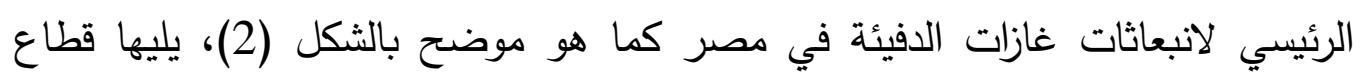

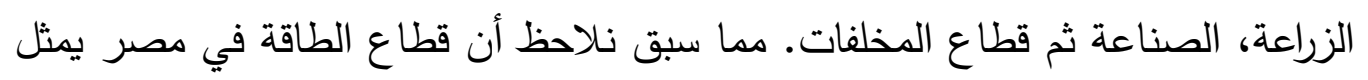

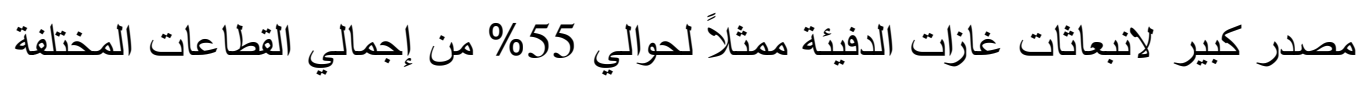

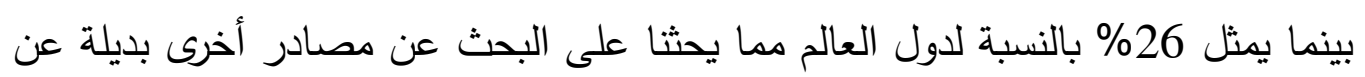

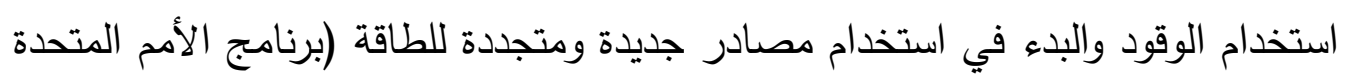
للمستوطنات البشرية، 2011). 
شكل (2): مصادر انبعاثات غازات الدفيئة عالميا

وطبقا للحالة المصرية في مختلف القطاعات

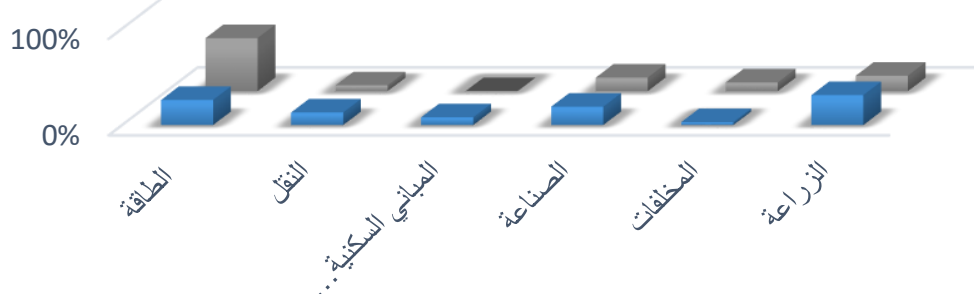

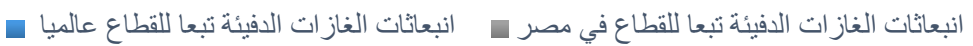

1-2-1 أسباب انبعاثات غازات الدفيئة

منذ الثورة الصناعية (على مدى الـ 250 سنة الماضية)، تم زيادة ظاهرة الاحتباس الحراري الطبيعية عن طريق التدخل البشرى كما هو موضح بالشكل (3). وغاز ثاني أكسيد الكربون واحد من غازات الدفيئة التي تم تعديلها عن طريق الأنشطة البشرية. شكل (3): التداخل البشري وظاهرة الاحتباس الحراري الطبيعية

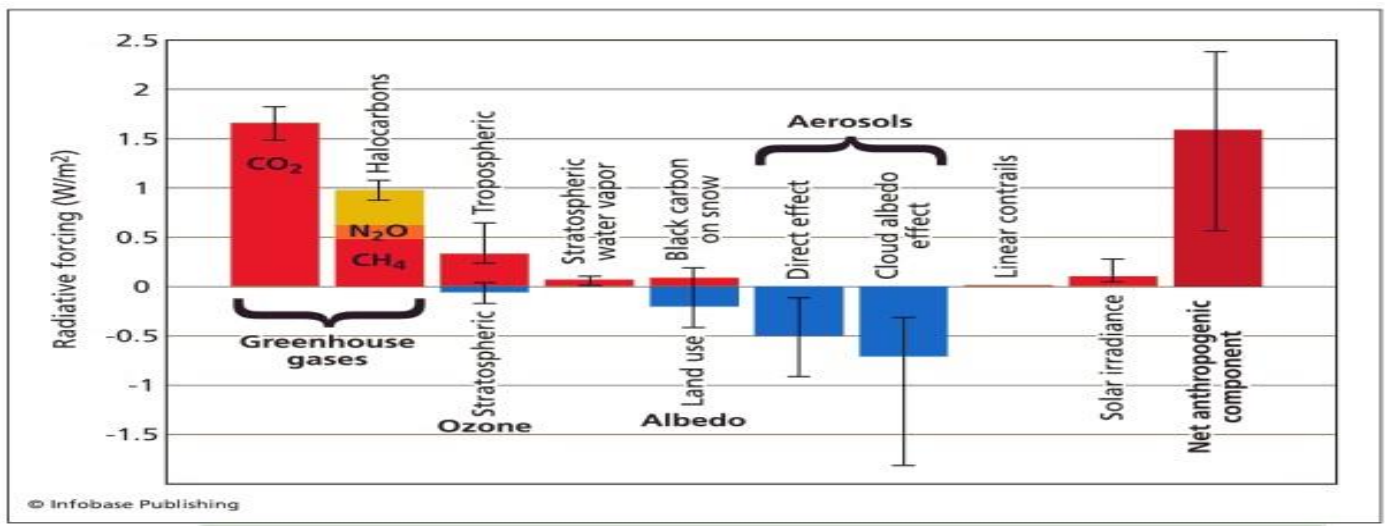

تؤدى التأثيرات الإشعاعية الإيجابية إلى احترار المناخ، أما التأثيرات السلبية تعمل على تبريد المناخ والعنصر البشري يعد واحدة من أكبر التأثيرات الإيجابية مما يرفع درجة حرارة الأرض لذا مطلوب على وجه السرعة إعادة صياغة لهذا المستقبل الحضري الذي يعتبر ذات أهمية حاسمة حيث أننا بحاجة إلى تصميم وتخطيط مدن بحيــــث تكون مستدامة ومنخفضة الكربون وملائمة للعيش. في السنوات الأخيرة كان هناك اهتمام متزايد حول دور المدن في كونها المحرك للنمو الاقتصادي (إنتاج ما يقرب من 80\% من الناتج المحلى الإجمالي). لكن هذا يعتبر جانب واحد فقط من القضية، حيث تستخدم المدن 67\% من مجموع استخدام الطاقة ومسئولة عن 71\% من من الإن انبعاثات غازات الدفيئة كما هو موضتح بالشكل (4). وتشير التقديرات إلى أن 89 في المائة من الزيادة في CO2 من استخدام الطاقة كانت من البلدان النامية (The World Bank,2010). 


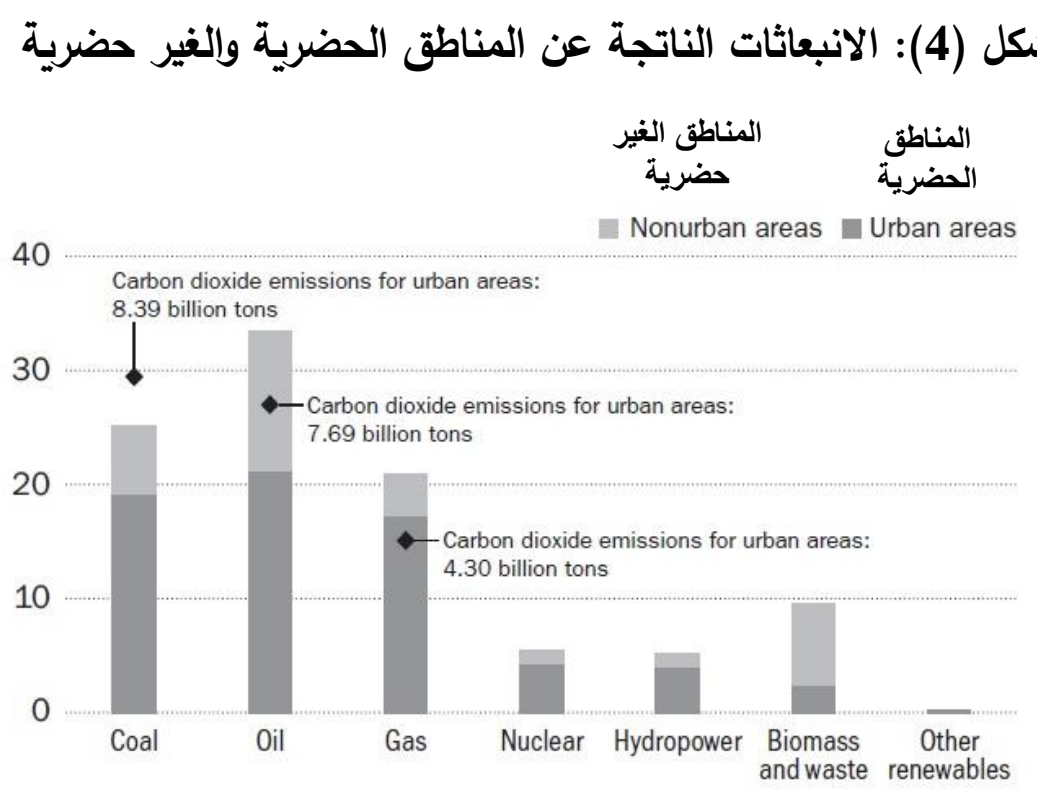

Source: The World Bank, 2010, p.19.

1-3-مظاهر انبعاثات غازات الافيئة

أ- الاحتباس الحراري هو زيادة في تركيز غازات الدفيئة تؤدى إلى انخفاض في الأشعة تحت الحمراء الخارجة، وبالتالي يتغير مناخ الأرض بطريقة أو بأخرى لاستعادة التوازن بين الأشعة الواردة والأشعة الخارجة. هذا "التغير" سوف يشمل " الاحتباس الحراري" لسطح الأرض والطبقة السفلى من الغلاف. زيادة درجات الحرارة بمعدل 0.6 خلا القرن الماضي (شكل رقم 5). وتوقع" الفريق الحكومي الدولي المعنى بتغير المناخ" في تقرير التقييم الثالث أن متوسط درجة (Holdren, حرارة سطح الأرض سوف ترتفع 1.4 - 5.8 درجة سيلزيوس بنهاية عام 2100 .2008

شكل (5): ارتفاع درجات الحرارة 0.6 درجة سيلزيوس خلال 125 سنة السابقة

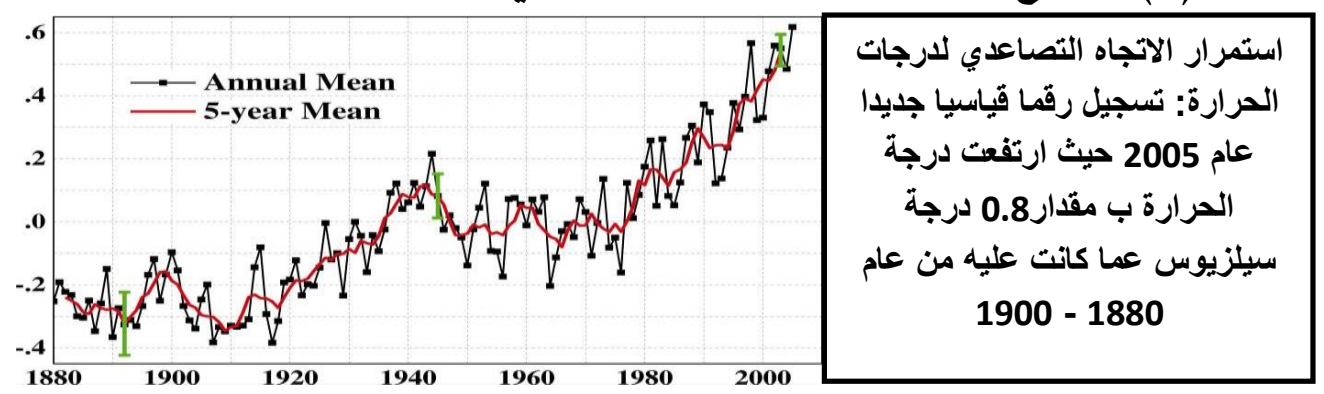

وتعتبر مصر من أكثر الدول التي يحتمل أن تشهد تغير ملحوظ في ارتفاع درجات الحرارة وامتداد فصل الصيف إلى شهر على الأقل كما هو موضح بالجدول (1). 


$$
\text { جدول (1): معدلات التغير في درجات الحرارة ومعدلات سقوط الأمطار }
$$

\begin{tabular}{|c|c|c|c|c|c|c|c|c|c|c|c|c|c|}
\hline & \multicolumn{5}{|c|}{ High Temperatures } & \multicolumn{3}{|c|}{ Low Temperatures } & \multicolumn{5}{|c|}{ Precipitation } \\
\hline & $\begin{array}{l}\text { Summer } \\
\text { Days }\end{array}$ & $\begin{array}{l}\text { Hot } \\
\text { days }\end{array}$ & $\begin{array}{c}\text { Tropical } \\
\text { nights }\end{array}$ & $\begin{array}{c}\text { Days }> \\
90^{\text {th }} \text { - } \\
\text { quantile }\end{array}$ & $\begin{array}{c}\text { Nights }> \\
90^{\text {th }} \text { - } \\
\text { quantile }\end{array}$ & $\begin{array}{c}\text { Frost } \\
\text { nights }\end{array}$ & $\begin{array}{l}\text { Ice } \\
\text { days }\end{array}$ & $\begin{array}{l}{ }^{(1)} \text { Days } \\
<10^{\text {th }} \\
\text { quantile }\end{array}$ & $\begin{array}{c}\text { Relative } \\
\text { Precip. } \\
\text { Var. }\end{array}$ & $\begin{array}{l}\text { Dry } \\
\text { days }\end{array}$ & $\begin{array}{l}\text { Rainfall } \\
\text { between } \\
1-10 \mathrm{~mm}\end{array}$ & $\begin{array}{c}\text { Max } \\
\text { 3-days } \\
\text { Rainfall }\end{array}$ & $\begin{array}{c}\text { Longes } \\
t \text { dry } \\
\text { spell }\end{array}$ \\
\hline $\begin{array}{l}\text { NW Iberian } \\
\text { Peninsula }\end{array}$ & 1 & 1 & & 1 & 1 & -1 & & -2 & & 2 & -2 & 3 & \\
\hline $\begin{array}{l}\text { South of France } \\
\text { (inland) }\end{array}$ & 3 & 1 & 1 & 2 & 2 & -1 & & -2 & -1 & 3 & -2 & 3 & \\
\hline $\begin{array}{l}\text { Coast of South of } \\
\text { France }\end{array}$ & 1 & & 2 & 2 & 2 & -1 & & -2 & -1 & 2 & -2 & 3 & 1 \\
\hline Corsica & 1 & 1 & 2 & 2 & 2 & -1 & & -2 & -1 & 2 & -1 & 2 & 1 \\
\hline Sardegna & 1 & & 3 & 2 & 2 & & & -3 & & 2 & -1 & 1 & 2 \\
\hline Sicily/South Italy & 3 & 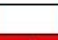 & 3 & 3 & 2 & & & -3 & & 3 & -1 & 3 & 3 \\
\hline North Adriatic & 3 & 3 & & 2 & 2 & -2 & -1 & -2 & -1 & 3 & -2 & 2 & 1 \\
\hline Central Balkans & 3 & 3 & & 2 & 2 & -2 & -1 & -2 & & 3 & -3 & & \\
\hline Central Greece & 2 & 1 & 2 & 2 & 2 & -1 & & -2 & -1 & 2 & -2 & 1 & 1 \\
\hline Peloponnese & 3 & & 3 & 2 & 2 & & & -3 & -1 & 2 & -1 & 2 & 2 \\
\hline Crete & 3 & & 3 & 3 & 3 & & & -3 & -1 & 2 & -1 & & 1 \\
\hline Coastal Turkey & \begin{tabular}{l|l}
1 & 2 \\
\end{tabular} & 1 & \begin{tabular}{l|l}
1 & 2 \\
\end{tabular} & 2 & 2 & -1 & & -2 & -1 & 2 & -1 & -1 & 1 \\
\hline Turkey Inland & $\frac{1}{3}$ & 3 & & 2 & 2 & -2 & -1 & -2 & & 3 & -2 & & 2 \\
\hline Cyprus & 1 & & 3 & 1 & 1 & & & -3 & -1 & 1 & 1 & & -1 \\
\hline $\begin{array}{l}\text { Lebanon-Israel- } \\
\text { Nile Delta }\end{array}$ & & 1 & & & & -1 & & -3 & (2) & 1 & -1 & & \\
\hline $\begin{array}{l}\text { E. Egypt -E. } \\
\text { Libya }\end{array}$ & 3 & 1 & 3 & 2 & & & & -3 & (2) & & -1 & & -1 \\
\hline W. Libya & & 1 & & 2 & - & & & -3 & & & -1 & & \\
\hline E. Maghreb & 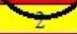 & 3 & 3 & 2 & 2 & -2 & & -2 & -3 & 2 & -2 & & \\
\hline W. Maghreb & 3 & 3 & 3 & 2 & 2 & -2 & & -2 & & 2 & -2 & -1 & 3 \\
\hline $\begin{array}{l}\text { South Tberian } \\
\text { Peninsula }\end{array}$ & 2 & 2 & 2 & 2 & 2 & -1 & & -2 & -1 & 2 & -2 & & 3 \\
\hline Central Spain & 3 & 3 & 1 & 2 & 2 & -2 & & -2 & -1 & 3 & -2 & -1 & 1 \\
\hline
\end{tabular}

يوضح الجدول معدلات التغير في درجات الحرارة وتظهر مصر في المناطق ذات التغيير الكبير حيث زيادة عدد

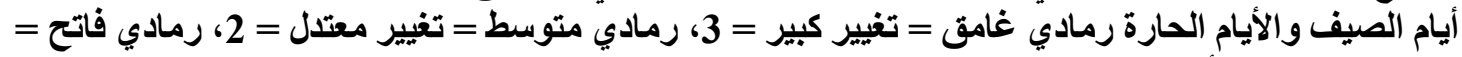
-Giannakopoulos, 2005, p. 35.

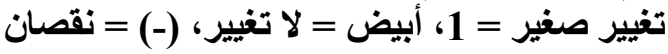

ب- ارتفاع مستوى سطح البحر إذا كان الاحتباس الحراري سيحدث فسوف يرتفع منسوب سطح

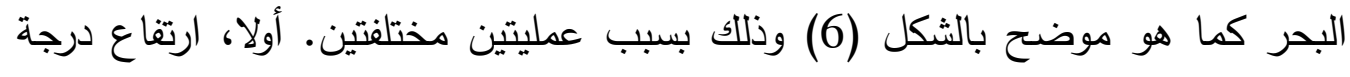
الحرارة سوف يؤدى إلى ارتفاع مستوى سطح البحر بسبب التمدد الحراري لمياه البحر.

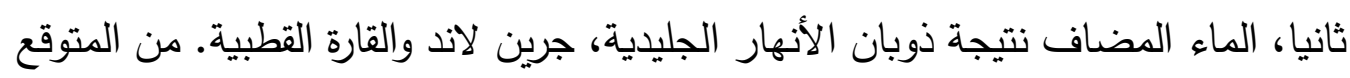

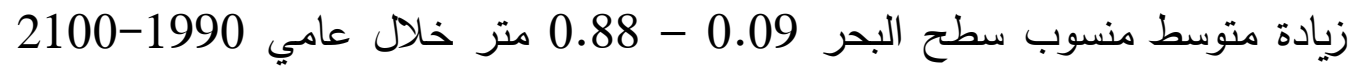

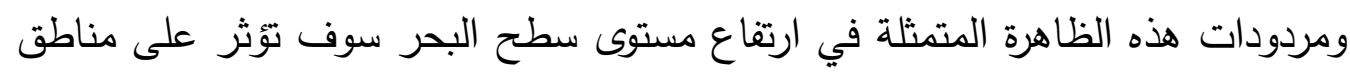
عديدة في مصر متمثلة في مناطق شمال الدلتا وتعرض بعضها للغرق مثل الإسكندرية، رشيد وبورسعيد) (Raey,2009). 


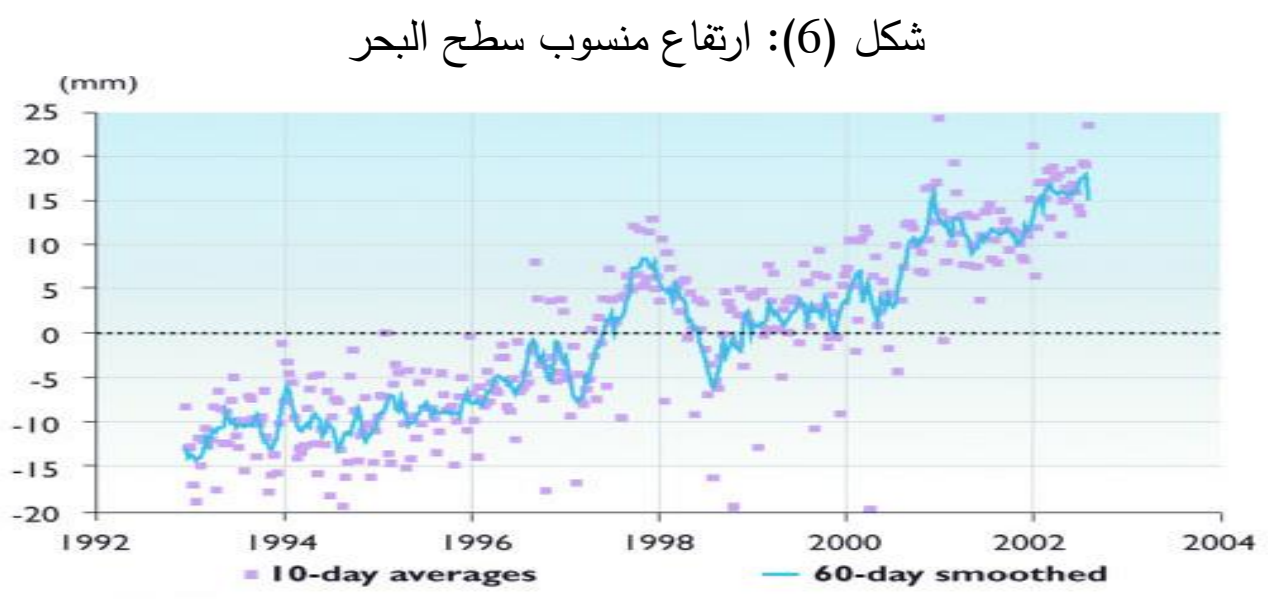

- Holdren, 2008, p. 17.

2-تأثيرات ظاهرة زيادة انبعاثات غازات الدفيئة 2-1. تأثيرات عمرانية (غرق المناطق الساحلية)، تعتبر دلتا النيل مع الساحل الأمامي للبحر المتوسط أكثر عرضة لتأثيرات الزيادة المتوقعة في منسوب سطح البحر، وتآكل الشواطئ، الضغط على مصايد الأسماك وتسرب المياه المالحة في المياه الجوفية تخلق تحديات كبيرة. تم وضع عدة سيناريوهات لتوقع العواقب السلبية على دلتا النيل. خرائط الأقمار الصناعية لدلتا النيل تظهر (Eldeberky, الأراضي التي سيتم خسارتها نتيجة سيناريوهات ارتفاع منسوب سطح البحر

(2011 كما هو موضتح بالجدول (2). جدول (2): أراضي سيتم خسارتها وعدد السكان المتضررين نتيجة سيناريوهات ارتفاع منسوب سطح البحر

\begin{tabular}{|c|c|c|c|}
\hline عدد السكان المتأثرين & نسب الأراضي المغمورة & الأراضي المغمورة & سيناريوهات ارتفاع سطح البحر \\
\hline 4 مليون & $\% 7.5$ & 1800 & 0.5 \\
\hline 6.1 مليون & $\% 18.9$ & 4500 & 1 م \\
\hline 8 مليون & $\% 23.9$ & 5700 & 1.5 \\
\hline
\end{tabular}

المصدر: الباحثين، وبتصرف اعتماداً على: (Eldeberky, 2011) 2-2. تأثيرات بيئية، منها تغير أنماطسقوط الأمطار ولا تعد مصر من الدول المعرضة للفيضانات نتيجة تغير معدل سقوط الأمطار ولكن تم ملاحظة أن انخفاضا بنسبة 10\% في سقوط الأمطار يمكن أن يؤدى إلى انخفاض بنسبة 31\% في تدفق النهر في الخرطوم، في حين أن زيادة 10\% في سقوط الأمطار قد يؤدى إلى زيادة بنسبة 36\% في تدفق المياه في نفس الموقع مما سيكون

له تأثير على موارد المياه (Egyptian Environmental Affairs Agency, 2013). 2-3. التأثير على الصحة، يشير جهاز شئون البيئة إلى أن العديد من القضايا الصحية الحالية في مصر يمكن أن تتفاقم بسبب تغير المناخ. كما أن ارتفاع درجات الحرارة من الممكن أن يزيد 
الإجهاد الحراري، خاصة في المناطق الحضرية مثل القاهرة والإسكندرية. ارتفاع درجات الحرارة والتغير في نسبة سقوط الأمطار من المكن أن يؤثر على توزيع الأمراض مثل الملاريا (Egyptian Environmental Affairs Agency,2013) إلى أن أمراض القلب والجهاز التنفسي والثرايين يثير قلق كبير في مصر . كما لوحظ من قبل

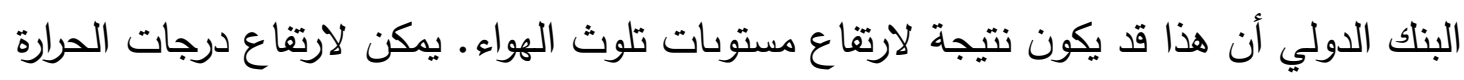

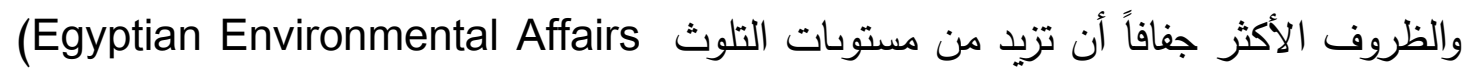

.Agency, 2013)

2-4 التأثير على النظم الأيكولوجية، حسب تقديرات العالم الأمريكي ويلسون فانه سوف ينقرض

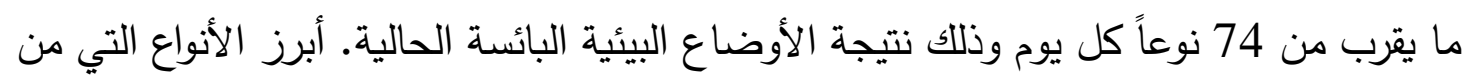

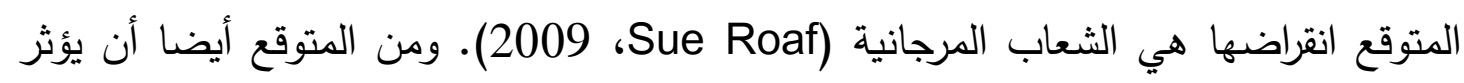

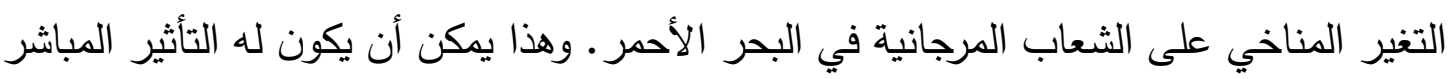
على نشاط السياحة لان العديد من السياح يأتون للغوص أو الغوص لمشاهدة الثعاب المرجانية الثرانية.

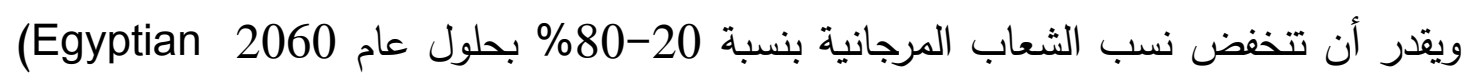

.Environmental Affairs Agency, 2013)

2-5 التأثير على الأنثطة الاقتصادية 1-5-2

- إنتاج المحاصيل في مصر سوف يتأثر عن طريق ثلاث طرق على الأقل من جراء التغير

$$
\text { المناخي: - (إختاج }
$$

- ارتفاع درجات الحرارة سوف يغير من إنتاج المحاصيل ومن الطلب على المياه

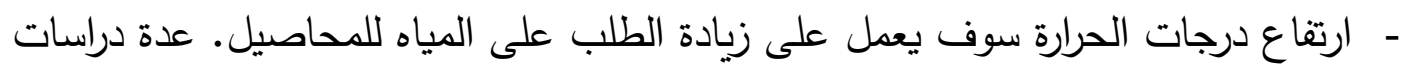

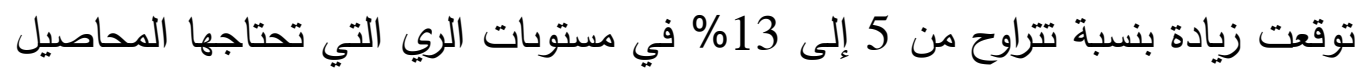

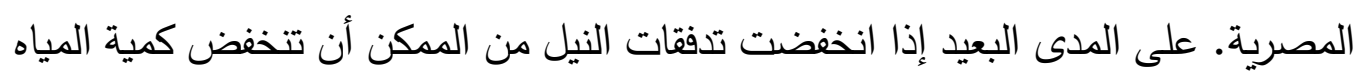
المطلوبة للري.

- ارتفاع منسوب سطح البحر قد يغمر الأراضي المنخفضة والأراضي الزراعية الغير محمية

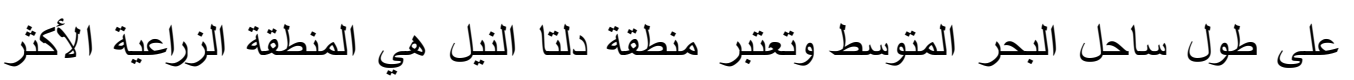
إنتاجيــة (Egyptian Environmental Affairs Agency, 2013). - الثروة الحيوانية، يمكن أن يؤثر ارتفاع درجات الحرارة إلى انخفاض إنتاجية الثروة الحيوانية،

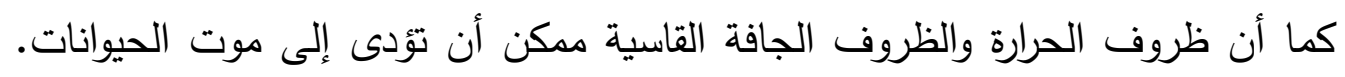

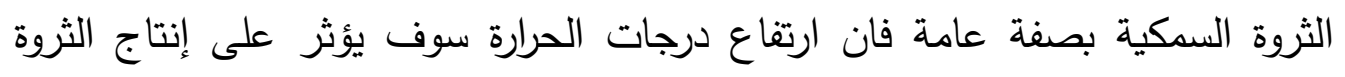


السمكية. بالإضافة إلى أن ارتفاع مستوبات الملوحة من المككن أن يحد من إنتاج اسماك

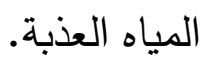

2-5-2 قطاع السياحة، تم إعداد سيناريو لتقدير قيمة الخسائر في عائدات نشاط السياحة نتيجة

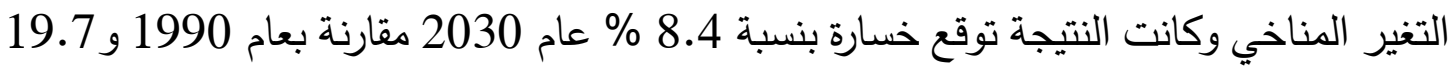
\% عام 2060 مقارنة بعام 1990. ويوضح الجدول (3) العائدات المقدر خسارتها نتيجة التغير

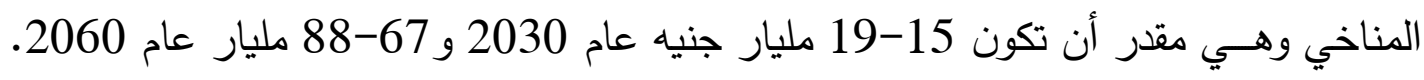
جدول (3): التأثيرات المتوقعة نتيجة التغير المناخي على العائدات السنوية لنشاط السياحة

\begin{tabular}{|c|c|c|}
\hline \multicolumn{3}{|c|}{ الخسائر نتيجة التغيرات المناخية (مليون جنيه } \\
\hline السيناريو المتفائل & السيناريو المتشائم & 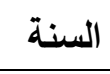 \\
\hline 14.735 & 18.856 & 2030 \\
\hline 67.103 & 88.386 & 2060 \\
\hline
\end{tabular}

من إعداد الباحثين، وبتصرف: (Egyptian Environmental Affairs Agency, 2013).

إذن كنتيجة نهائية لهذا الجزء فان النقطة البحثية تدور حول زيادة انبعاثات غازات الدفيئة نتيجة

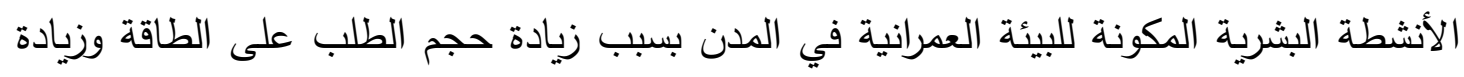

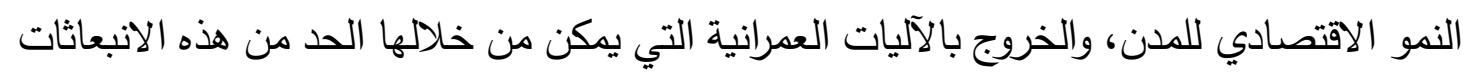

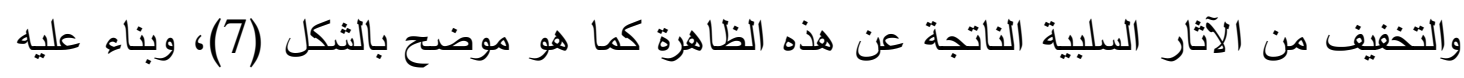
سيتناول البحث في الجزء التالي عرض لآليات التعامل مع هذه الظاهرة من خلال دراسة للأسس النظرية والتجارب العالمية المختلفة. 
شكل (7): دراسة للقطاعات المسببة للمشكلة ومقترحات التعامل

الباحث بناء على نتائج الدراسات النظرية

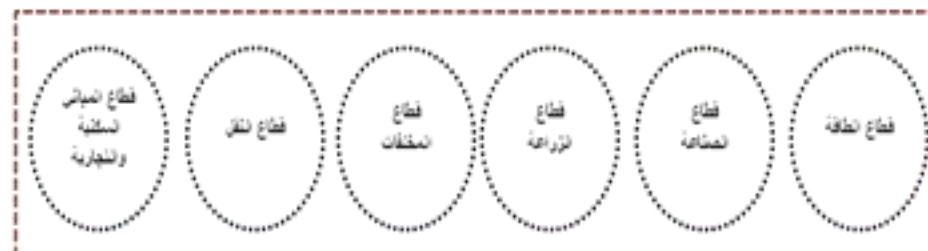

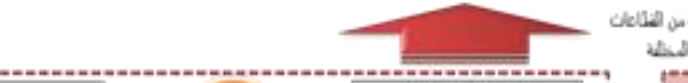

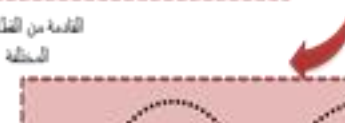

incilaiflion vas

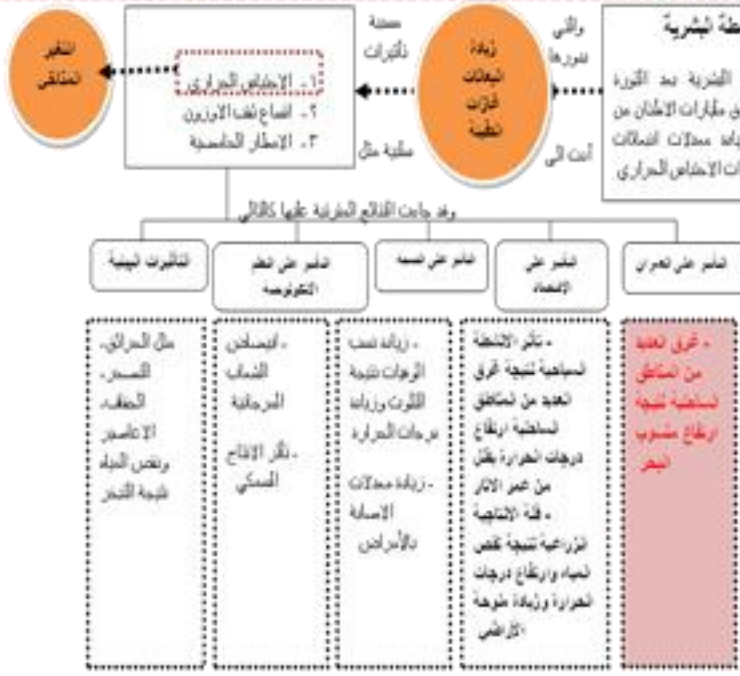

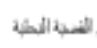
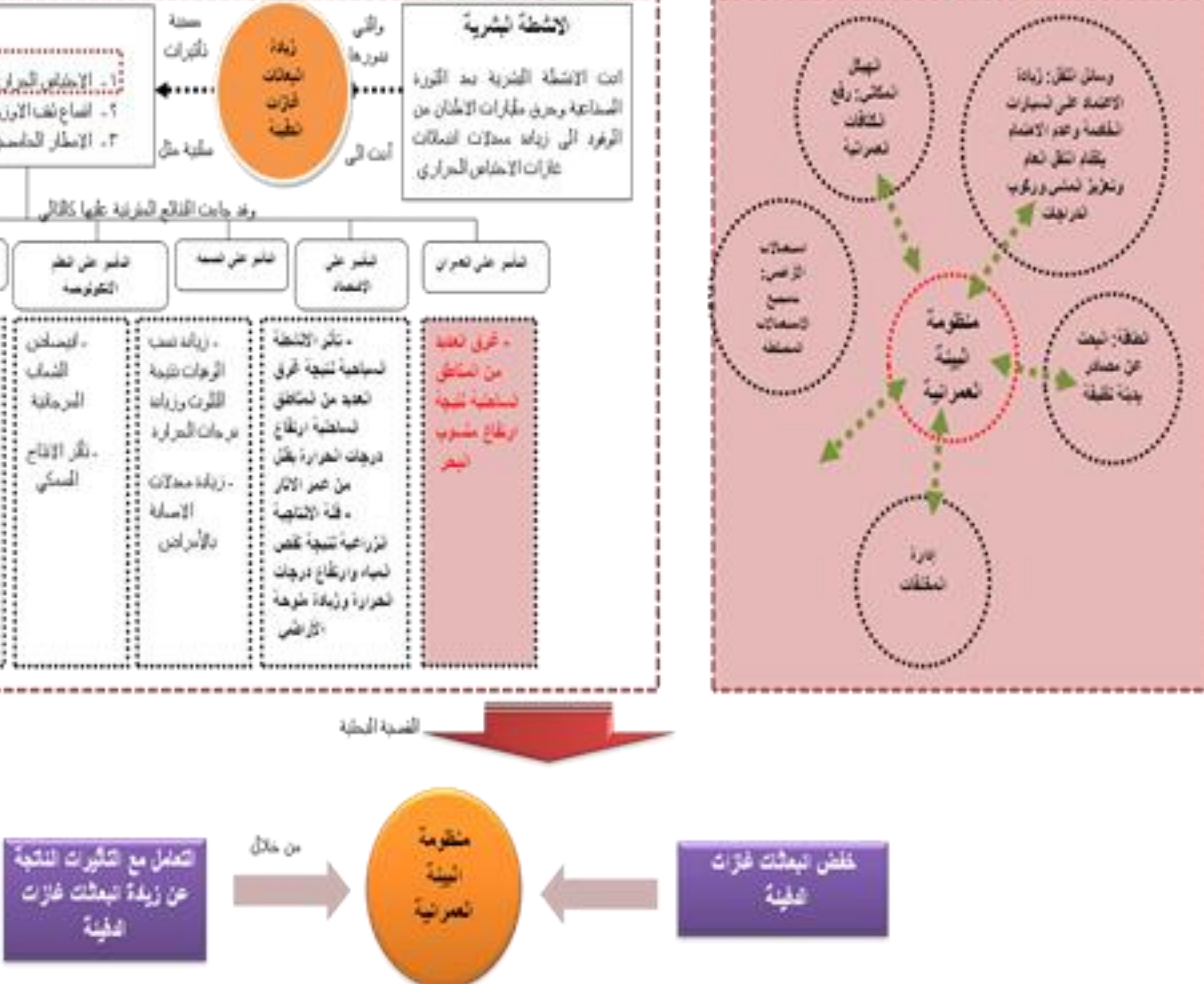

3

تم من خلال الجزء الأول من البحث تعريف القطاعات المختلفة المسببة للمشكلة، سيتاول هذاتهات الجزء من البحث دراسة الأسس النظرية للتعامل مع هذه الظاهرة من خلال دراسة لمجموعة من

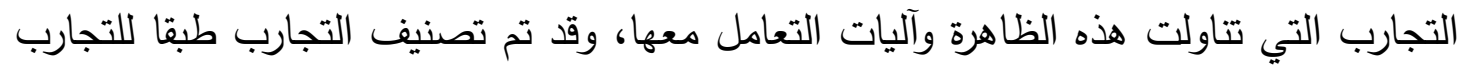
التي تبنت آليات التخفيف للحد من مسببات هذه الظاهرة من القطاعات العمرانية المختلفة، وطبقا للتجارب التي تبنت آليات التكيف للتعامل مع النتائج المترتبة على زيادة انبعاثات غازات الدفيئة المتمثلة في غرق العديد من السواحل نتيجة ارتفاع منسوب سطح البحر ـ ومن خلال منهج تحليلي

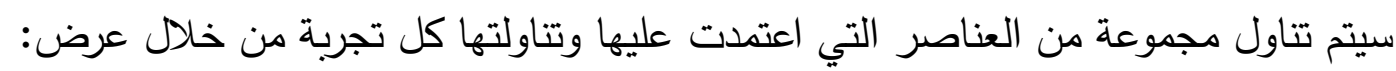
- - الشكلة مؤشراتها ومظاهرها

$$
\text { - }
$$




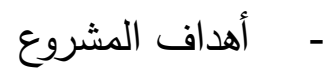 \\ - - الآليات التخطيطية للحد من وتقليل تأثيرات المشكلة

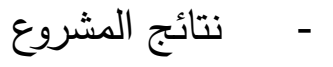 \\ 1-3. الأسس النظرية للتعامل مع ظاهرة زيادة انبعاثات غازات الدفيئة} سيتم تناول الأسس النظرية لمواجهة ظاهرة زيادة انبعاثات غازات الافيئة من خلال التكيف مع الأثار المترتبة على هذه الظاهرة، وفيها سيتم عرض الأسس المختلفة للتكيف مع غرق المناطق الساحلية نتيجة ارتفاع منسوب سطح البحر وعن طريق التخفيف من وتقليل هذه الانبعاثات من خلال القطاعات المختلفة المكونة للمدينة مثل قطاع النقل، الطاقة، استعمالات الأراضي، المخلفات الصلبة وقطاع الصناعة، ويوضح الشكل (8) مجموعة الأسس التي تم الخروج بها للتعامل مع الظاهرة.

شكل (8): الأسس النظرية للتعامل مع ظاهرة زيادة انبعاثات غازات الدفيئة

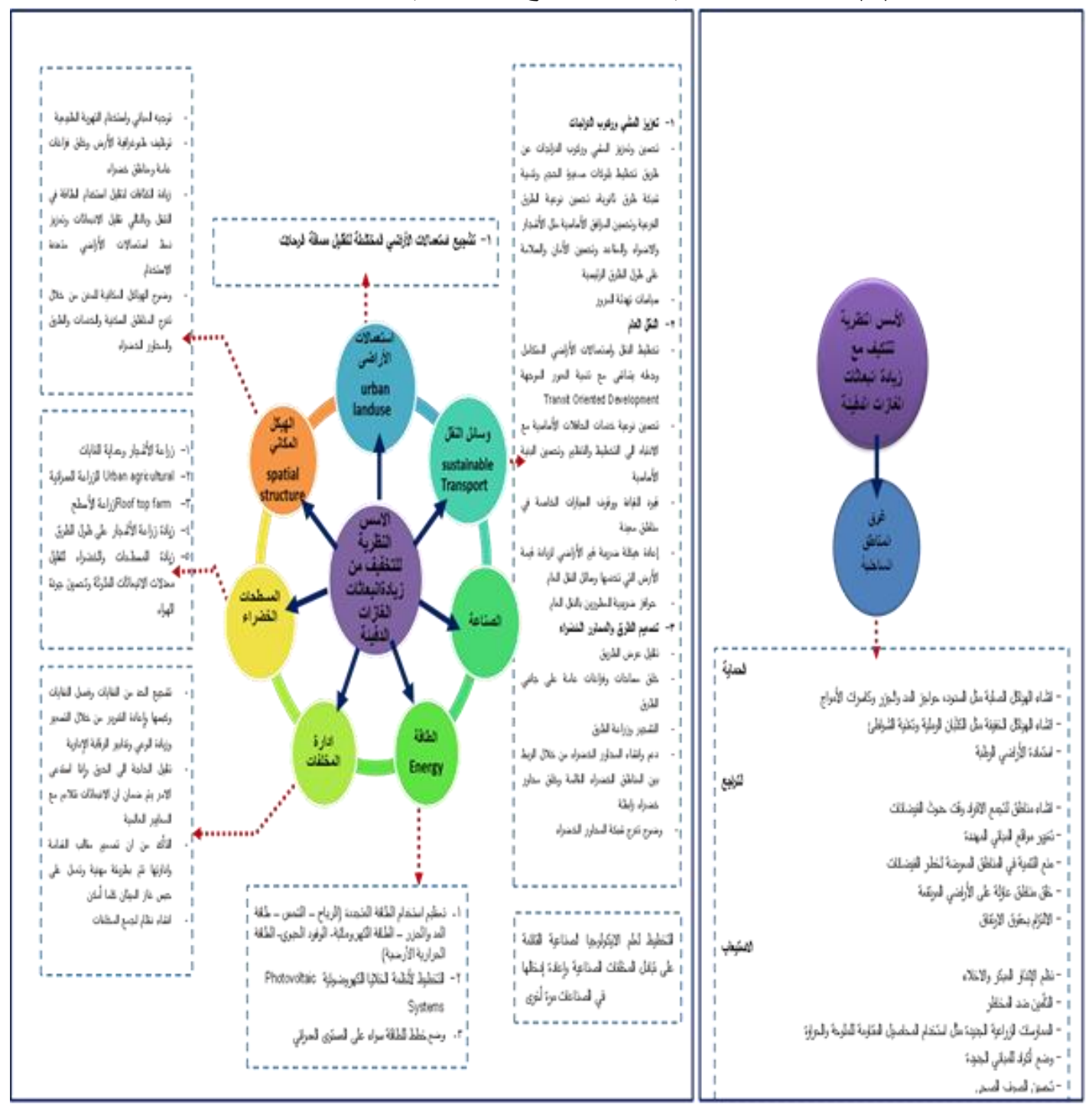




\section{2-3 التجارب العالمية للتعامل مع ظاهرة زيادة انبعاثات غازات الافيئة} يهدف هذا الجزء إلى دراسة لمجموعة من التجارب التي تتاولت هذه الظاهرة وآليات التعامل معها، وقد اعتمد منهج تصنيف التجارب طبقا للتجارب التي تبنت آليات التخفيف للحد من مسببات هذه دهات التهات

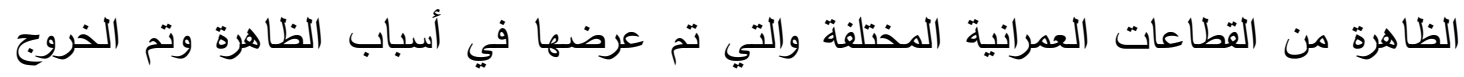
بالقطاعات الرئيسية المسببة في زيادة انبعاثات غازات الدفيئة متمثلة في قطاع الطاقة، النقل فئل

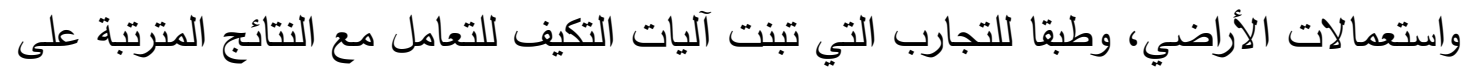
زيادة انبعاثات غازات الدفيئة المتمثلة في غرق العديد من السواحل نتيجة ارتفاع منسوب سطح

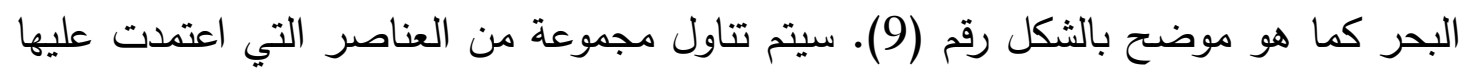

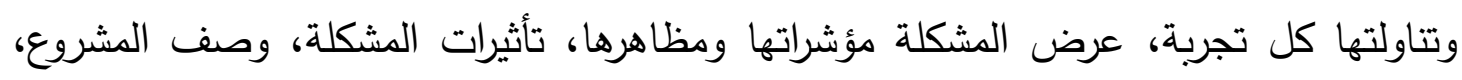
أهداف المشروع، الآليات التخطيطية للحد من وتقليل تأثيرات المشكلة، نتائج المشروع. شكل (9): منهجية تصنيف التجارب

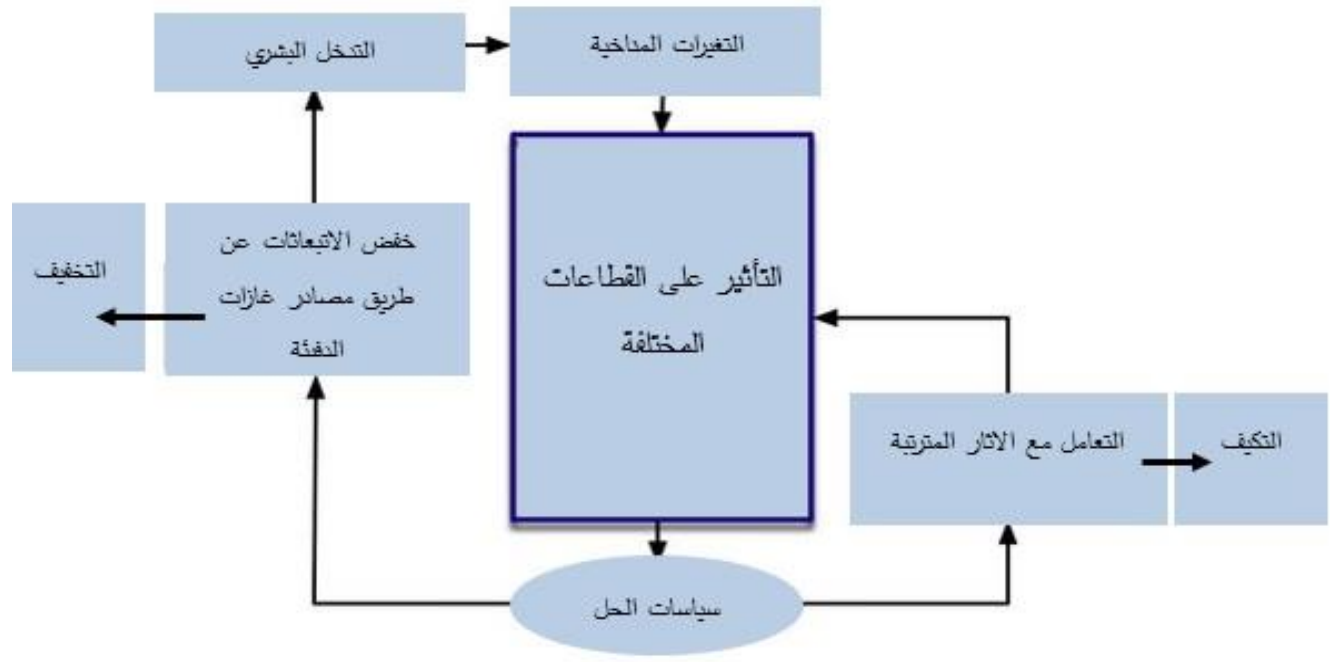

1-2-3 التجارب التي تبنت مداخل وآليات التكيف (إدارة السواحل: التجربة الهولندية)

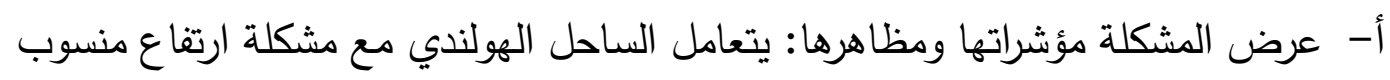

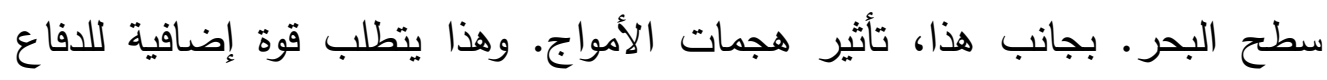
الساحلي. ب- تأثيرات المشكلة يقول خبراء المناخ أن مستوى البحر ارتفع 19 سنتيمترا بين العامين

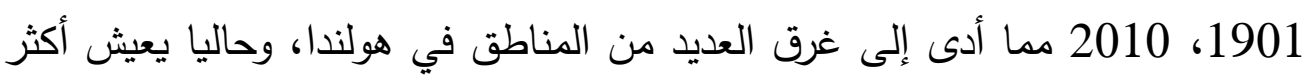
من نصف سكان هولندا في مناطق أدنى من منسوب سطح البحر (Roggema)،

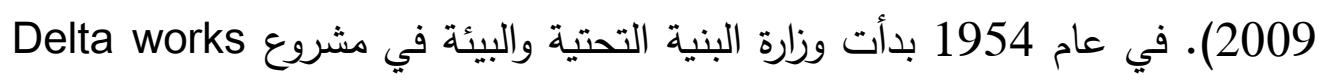
وقد الانتهاء منه عام 1997 مع أكثر من 16500 كم من السدود بمجموع 13 سدا 
جنوب غرب هولندا للحماية من خطر الفيضانات. الأهداف التي تبنتها التجربة تعزيز حماية المناطق الساحلية والمناطق المنخفضة المنسوب من الغرق. ت- الآليات التخطيطية للحد من وتقليل تأثيرات المشكلة

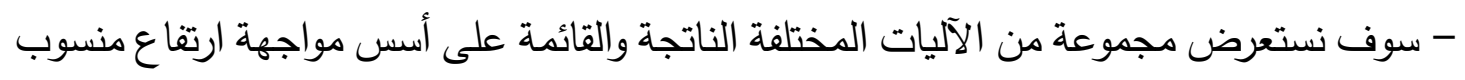
سطح البحر وحماية العديد من المناطق من خطر الغرق ومن ضمن الآلآليات التي سيتم تتاولها:

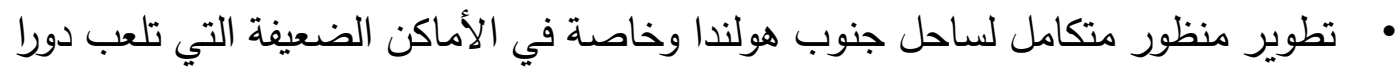

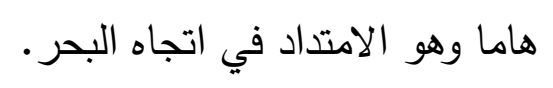

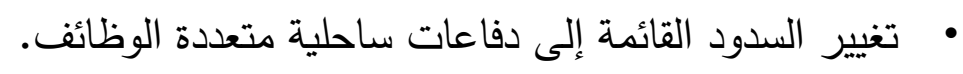

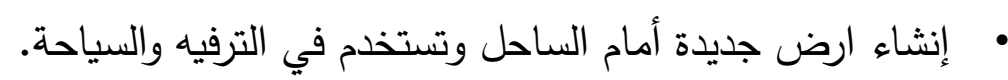

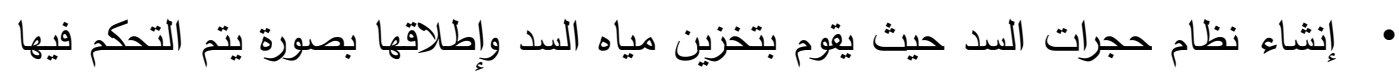
مما يقلل من خطر الفيضان. بالإضافة إلى، عمل أماكن لتجمع الناس في حالات الفيضان. •إنشاء مناطق تستوعب مياه الفيضان ويمكن تخزين مياه المطر فيها وتكون هذه المناطق مركزة في المناطق العمرانية. توسيع المنطقة الساحلية حيث التطوير البيئي بالإضافة إلى إنثاء مناطق جذب معيشة جديدة. • بناء سدود جديدة، فاذا تم إصلاح السد القديم وصيانته فسوف يعمل كخط دفاع ثاني ويمنع مياه الفيضان من المرور.

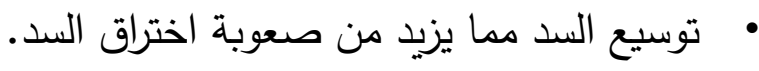

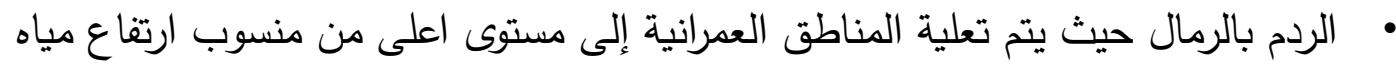
البحر للحفاظ عليها. بناء جزر جديدة أمام الساحل لحمايته حيث تعمل الجزر على تقليل شدة الأمواج في حالات الدد والجزر والأعاصير. • إنشاء جزر الميناء والتي تهدف إلى حماية الساحل عن طريقة تهيئة الأمواج، وسوف يجمع بين وظائف الميناء مع توليد الطاقة. 2-2-3 تجارب تبنت مداخل وآليات التخفيف للتعامل مع ظاهرة زيادة انبعاثات غازات تتقسم التجارب التي تبنت آليات التخفيف إلى عدة أنواع، منها تجارب للتخفيف من زيادة انبعاثات

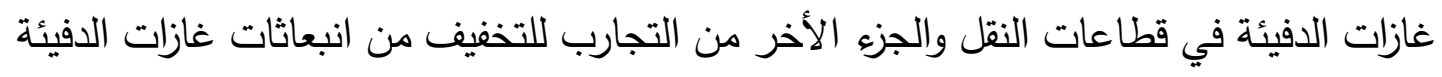


بقطاع الطاقة، الجزء الأخير من التجارب سيتم عرض كيفية التخفيف من انبعاثات غازات الدفيئة من خلال استعمالات الأراضي.

1-2-2-3 قطاع النقل: التجربة الصينية (مدينة غوانغتشو : نظام عبور حافلات النقل السريع) تكامل استعمالات الأراضي مع النقل العام وتثجيع المرور العابر

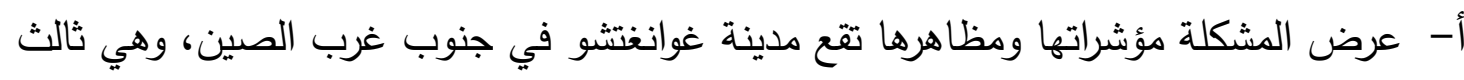

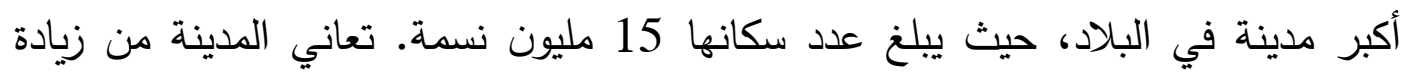

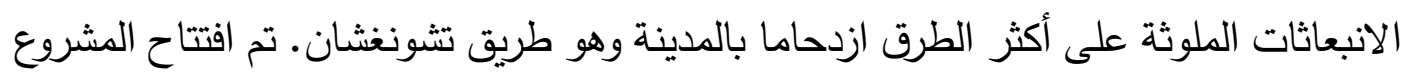
عام 2010 بطول 22.5 كيلومتر . ب- تأثيرات المشكلة زيادة معدلات التلوث والازدحام المروري بالمدينة مما يؤدي إلى صعوبة وصول الأفراد.

ج- وصف المشروع: يبدأ المشروع في الطرف الغربي لمنطقة تيانهى، حيث التنمية الكثيفة على ولى الترد

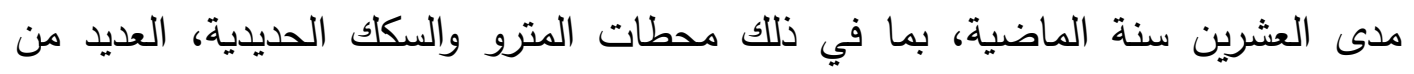

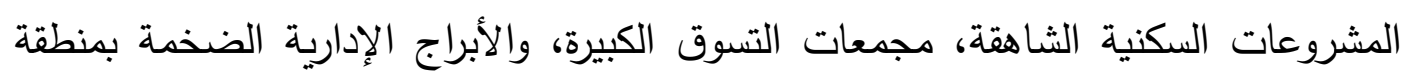

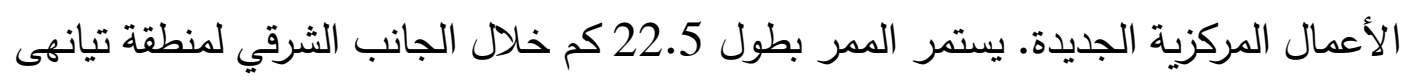

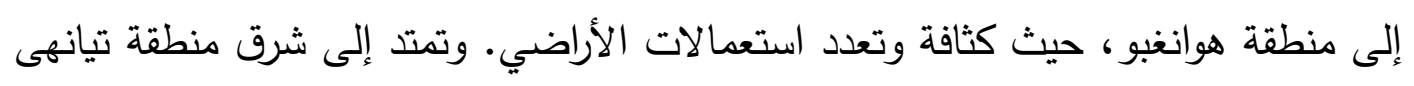

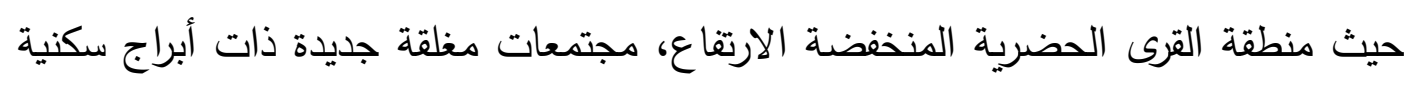

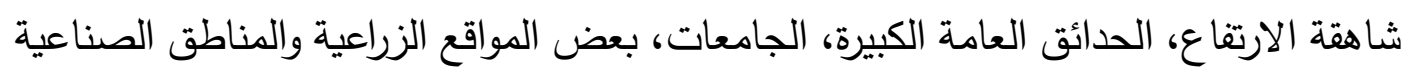

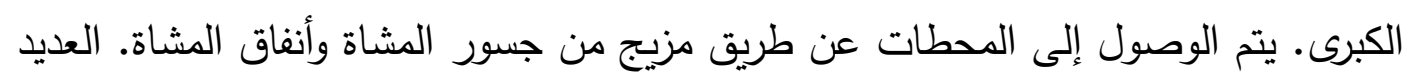

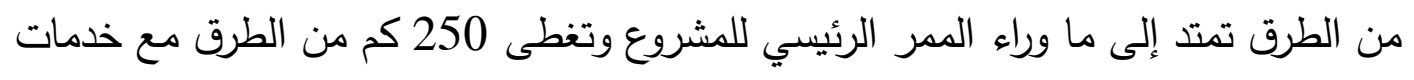
المرور العابر السربع للحافلات (Suzuki, 2013).

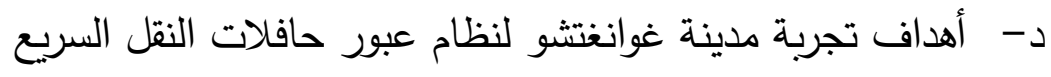

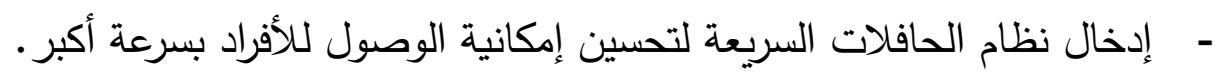

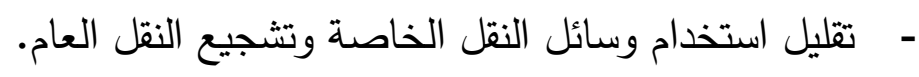

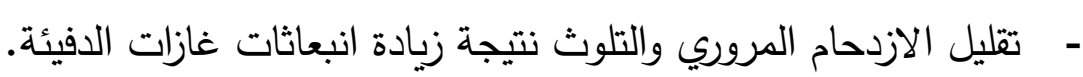

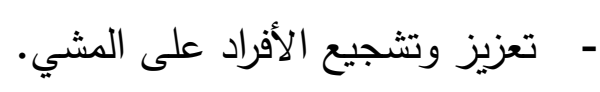
- - ميادة المسطحات الخضراء والفراغات العامة. - - تعزيز البنية الأساسية لوسائل النقل الغير ميكانيكية. - - التكامل بين وسائل النقل الميكانيكية والغير ميكانيكية. 
هـ - الآليات التخطيطية للحد من وتقليل تأثيرات المشكلة ودمج وسائل النقل وتحسين البيئة المحيطة

-:(Suzuki, 2013)

- - م ت تدعيم الاستثمار في المرافق التي تعزز التكامل بين وسائل النقل الغير ميكانيكية وبين

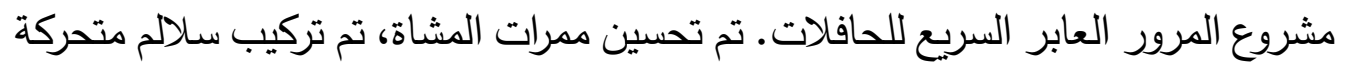

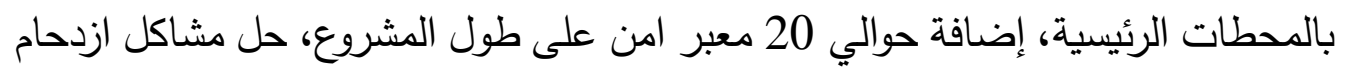

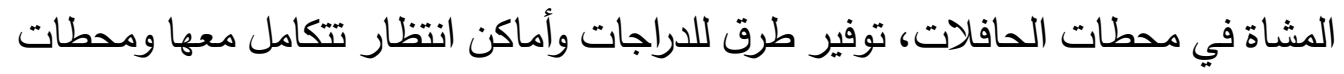
الداجات التي يتم تثاركها. - تحسين الفراغات العامة بالقرب من المشروع عن طريق تطوير حدائق عامة بطول المشروع. - البدء في مشروع تحسين المحاور الخضراء عام 2010، لخلق مئات الكيلومترات من

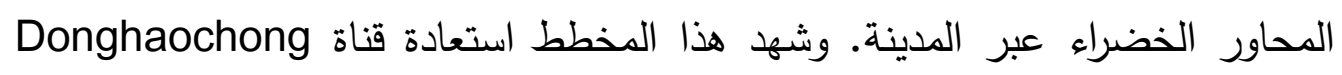

$$
\text { القديمة (وأصبحت جزء ترفيهي رئيسي بالششروع). }
$$

- تطوير 329000 متر مربع من العقارات التجارية الجديدة بالمنطقة المحيطة لجذب الأفراد للعيش والعمل والترفيه. - - تكثيف وتتويع استعمالات الأراضي يجرى في الجزء الغربي من المشروع، حيث يتم تثييد

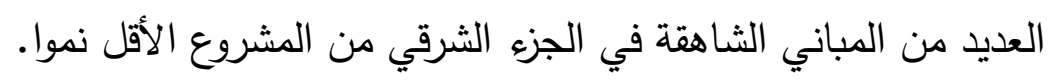

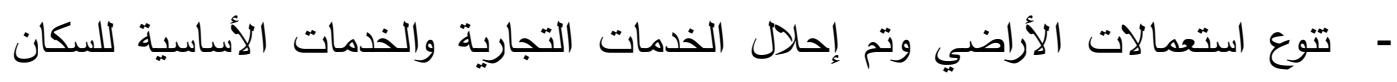

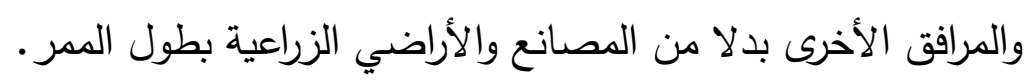

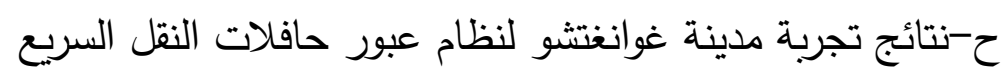

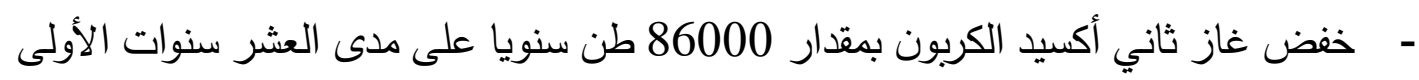
بقيمة خفض انبعاثات سنوية تقدر بقيمة 2.8 مليون دولار (Suzuki, 2013).

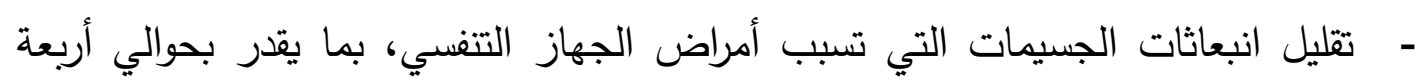

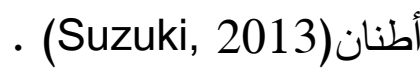

2-2-2-3 قطاع الطاقة: التجربة الإسبانية (مدينة برشلونة: تحسين أداء الطاقة)

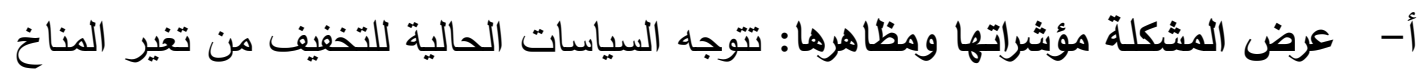

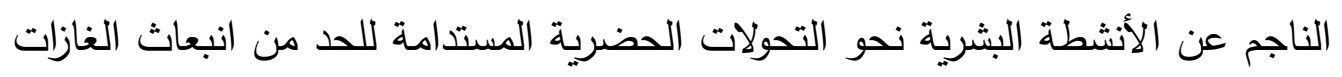

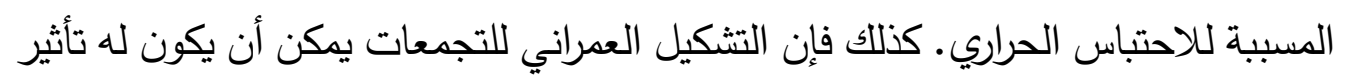

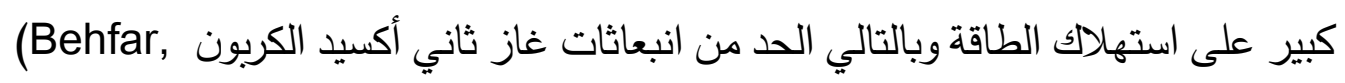


ب- تأثيرات المشكلة: ينفق حوالي50\% من استهلاك الطاقة كل عام على الكهباء لكل فرد،

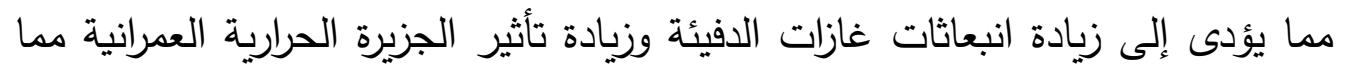

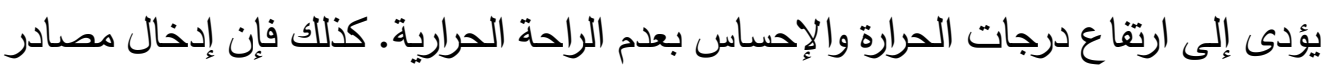
الطاقة المتجددة سيعمل على تقليل انبعاثات غاز ثاني أكسيد الكربون. ج- وصف المشروع: وسيتم تتاول هذا في كيفية تحويل مجاورة سكنية إلى نظام أقل في تئي استهلاك الطاقة وذلك باستخدام IMM (Integrated Modification Methodology) في الواقع، يمكن استبدال المباني التقليدية القائمة المستهلكة للطاقة من خلال المباني ذات اتلات

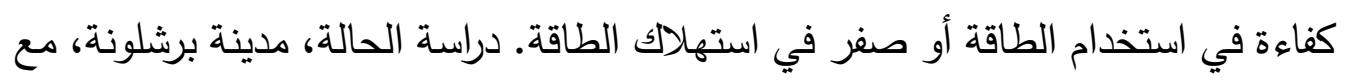
متوسط إثعاع شمسي حوالي 1500 كيلو واط/ ساعة/ م2/ سنة لايها القدرة على إنتاج كمية كبيرة من الطاقة. ارتباط منهجية IMM مع منهجية التخفيف من الجزيرة الحرارية

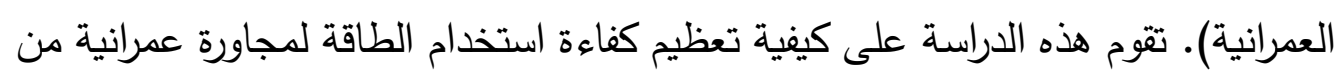

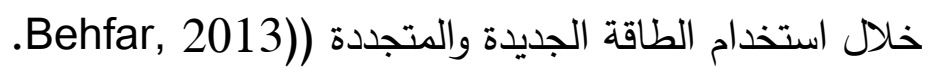
د- أهداف المشروع: تحقيق كفاءة الطاقة باستخدام الطاقة الجديدة والمتجددة والمحاور

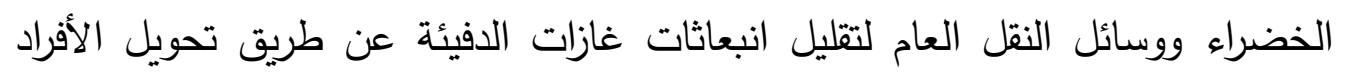
لساحات أربعة بلوكات عمرانية إلى فراغات عامة مستدامة، تخدم المنطقة المحيطة. إعادة التهات

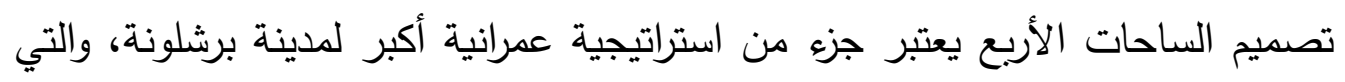
تهدف إلى استرداد عدد محدد من الساحات. هـ - الآليات التخطيطية لتجربة مدينة برشلونة: تحسين أداء الطاقة تحديث الطاقة (Behfar, 2013). - الاعتماد على توليد الطاقة من المصادر المتجددة التي تتكون من الألواح الكهروضوئية ومجمعات الطاقة الثمسية. - تم اختيار المواقع على أسطح المباني، واجهات المباني والساحات العامة.

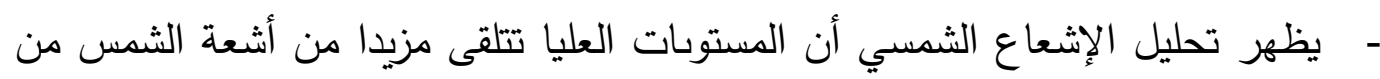
المستونات العليا. - كما أن هناك بعض واجهات المباني التي لها قدرة على تلقى مزيد من أشعة الثمس مثل الأسطح العليا. - تم تجهيز مجمعات الطاقة الثمسية مع خزانات المياه ليتم استخدام الماء الساخن في الفترات التي يكون فيها الاشعاع الثمسي غير كافي. 
- - تركيب الألواح الضوئية في فراغات مفتوحة حيث لا يوجد تأثير للتظليل يمنع انتاج الطاقة،

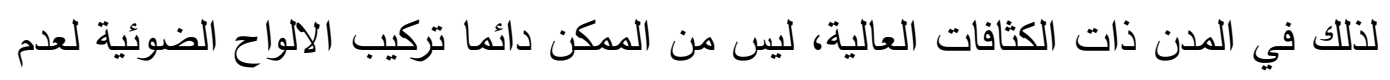
وجود فراغات مفتوحة كافية. و -نتائج تجربة مدينة برشلونة: تحسين أداء الطاقة فراغة

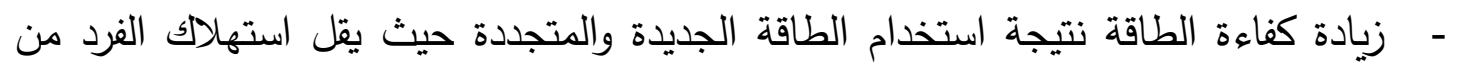

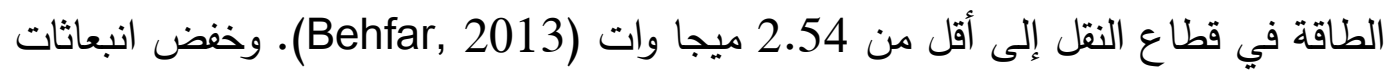
غاز ثاني أكسيد الكربون نتيجة استخدام الطاقة الجديدة والمتجددة.

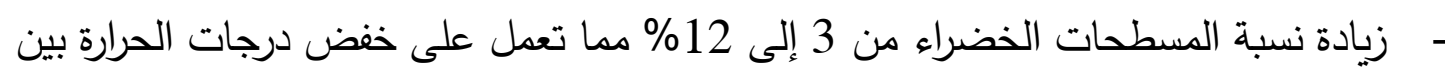
0.24 - 0.96 درجة سيلزيوس (Behfar, 2013).

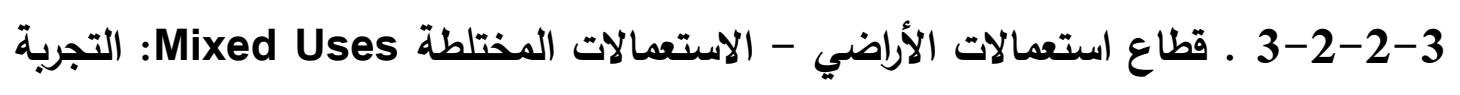
(MIAMI-DADE COUNTY, FLORIDA) الأمريكية أ- عرض المشكلة مؤشراتها ومظاهرها تقع مقاطعة MIAMI-DADE في الجنوب الشرقي

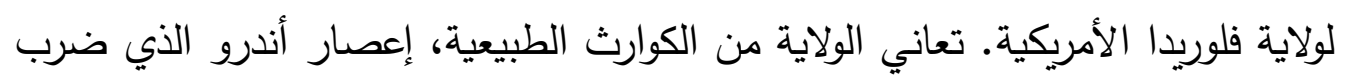

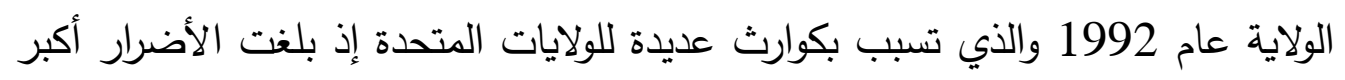

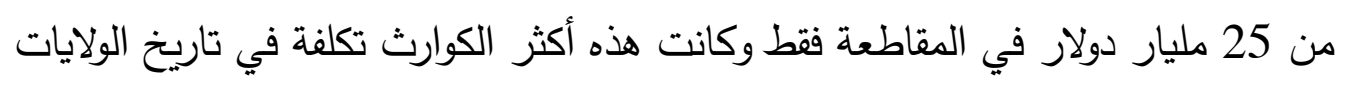

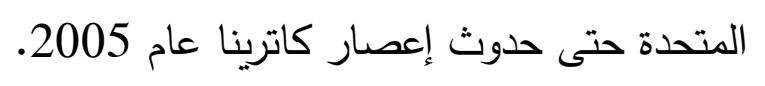

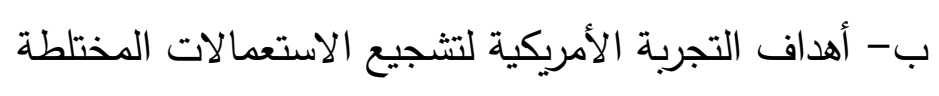

$$
\text { - - تشجيع التنمية ذات الاستعمالات متعددة الاستخدامات. }
$$

الآليات التخطيطية عام 1990؛ كانت تختبر العديد من المجتمعات في مقاطعة Miami-Dade

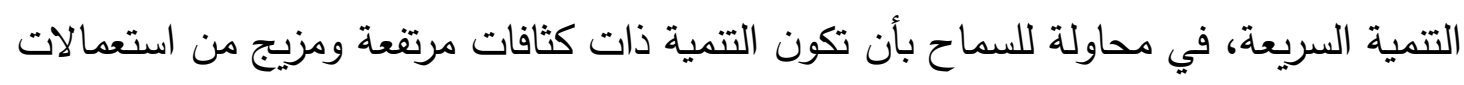

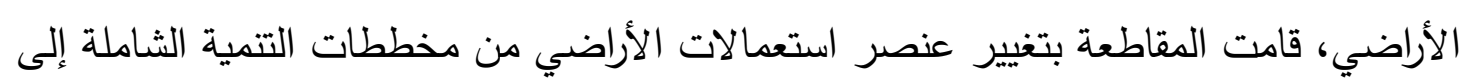

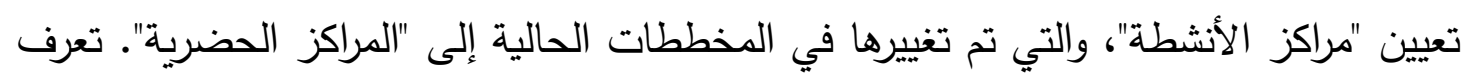

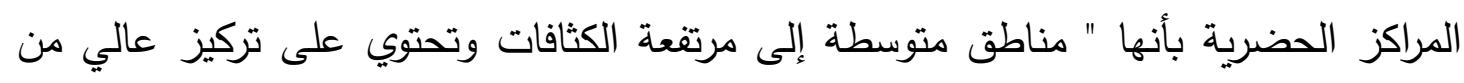

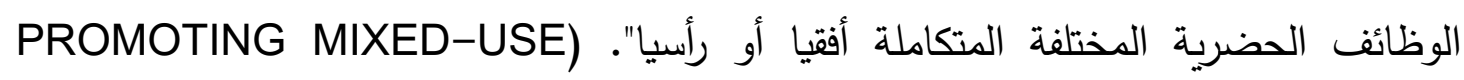


لتحفيز الاستعمالات متعدة الاستخدامات قامت المقاطعة بتحديد متوسط للكثافات ونسب البناء

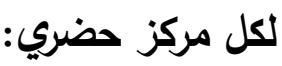

- - المراكز الإقليمية: نسب المساحة المبنية يجب أن تكون أكبر من 0.4 في القلب والا تقل عن 0.2 على الأطراف، اقصى كثافة 500 وحدة سكنية للفدان.

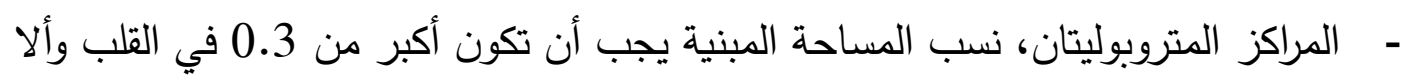
تقل عن 0.75 على الأطراف، اقصى كثافة 250 وحدة سكنية للفدان.

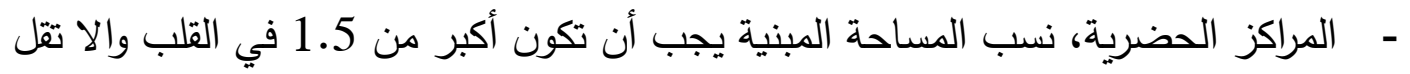
عن 0.5 على الأطراف، اقصى كثافة 125 وحدة سكنية للفدان.

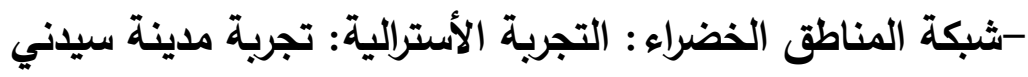

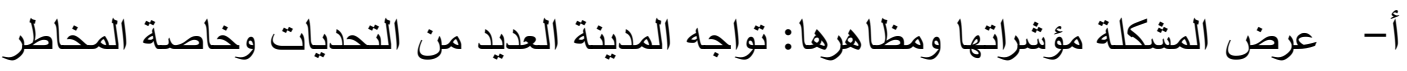
المرتفعة بسبب ظاهرة الاحتباس الحراري وقد عزز هذا التقارير الوطنية والدولية بشأن

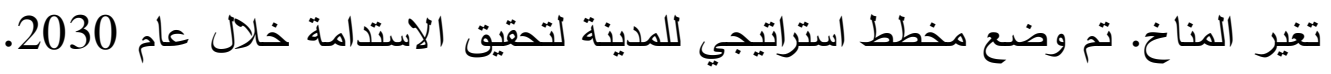

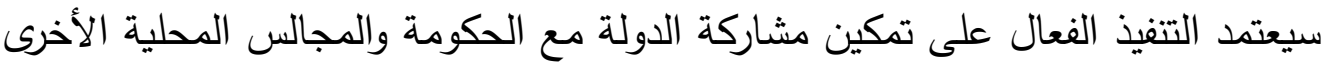

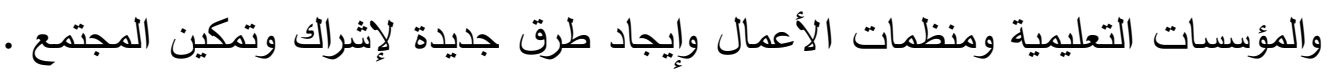

(SGS Economics \& Planning, 2008)

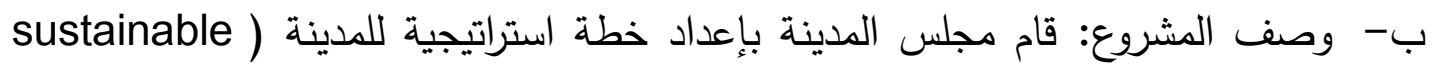

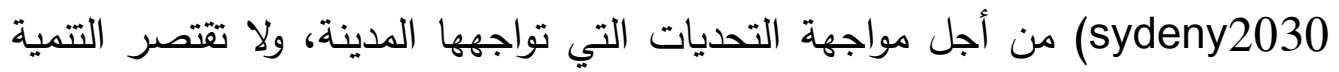
على البيئة المادية فقط، ولكن حول الاقتصاد والمجتمع. وتعتمد رؤية المدينة على ثلاثة أهداف رئيسية مدينة خضراء، مترابطة وعالمية وعناصر تحقيق هذه الرؤية.

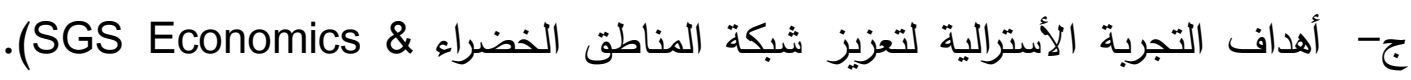

Planning, 2008) -

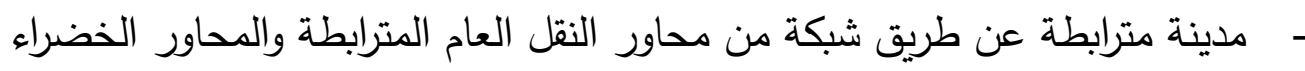

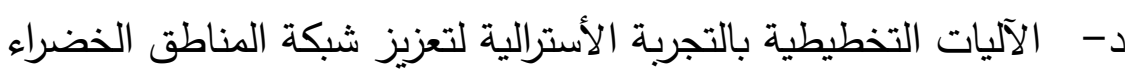

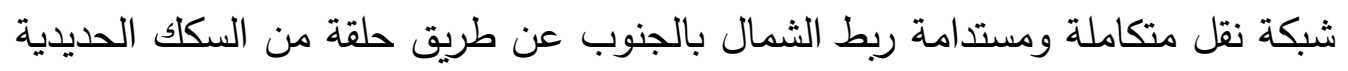
الخفيفة والتي تربط مركز الدينة بالمناطق المحيطة.

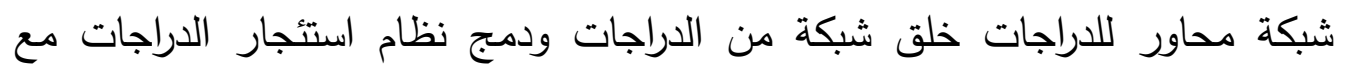
تقاطعات النقل ومراكز الأنشطة، مثل التسوق، الترفيه والعمل.

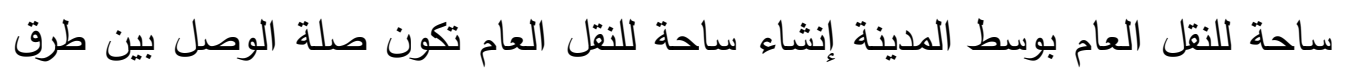
النقل العام، لتقليل الحاجة للحافلات والمركبات للمرور عبر مركز المدينة. 


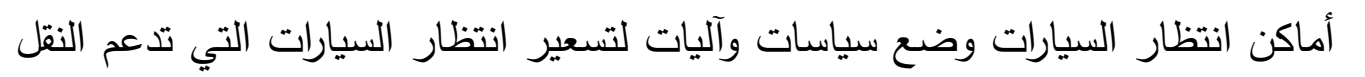
الأخضر، إدارة مواقف انتظار السيارات التي تقلل عدد السيارات في مركز الدينة.

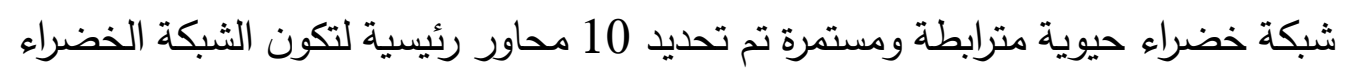
الدقترحة بالمدينة وقد تم اختيار هذه المحاور لأنها تربط النقاط الهامة والرئيسية بالددينة.

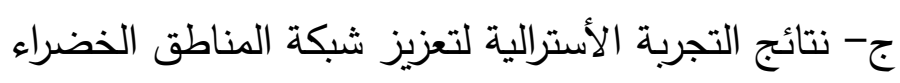

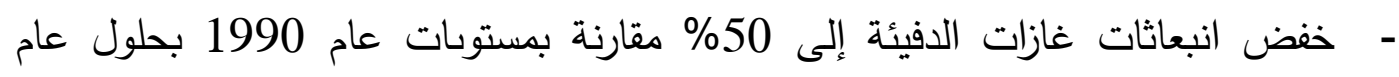

$$
.2030
$$

- - زيادة الرحلات باستخدام وسائل النقل العام للذهاب إلى العمل إلى 80\% بحلول عام

$$
.2030
$$

- زيادة رحلات المدينة باستخدام الدراجات إلى 10\% والرحلات عن طريق المشي إلى

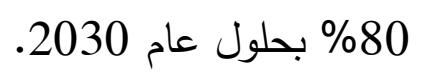

\section{4-آليات التعامل مع الظاهرة طبقا لاراسة التجارب العالمية} يوضح الشكل رقم (10) الآليات التي تم استتاجها من دراسة التجارب العالمية المختلفة للتعامل مع ظاهرة زيادة انبعاثات غازات الدفيئة وقد تم تصنيفها طبقا للآليات التي تعاملت مع النتائج

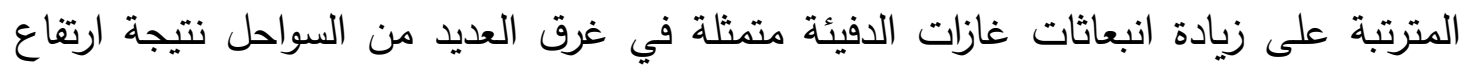
منسوب سطح البحر (آليات التكيف)، وآليات التخفيف وهي التي تتعامل مع كيفية خفض التضات انبعاثات

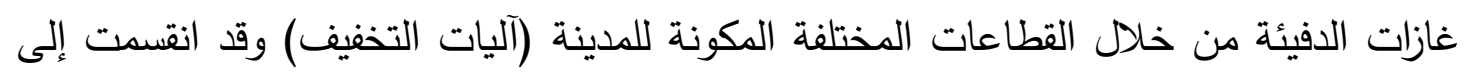

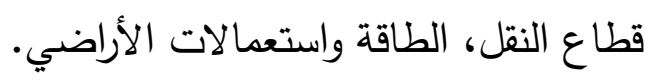
شكل (10): آليات التعامل مع ظاهرة زيادة انبعاثات غازات الدفيئة طبقا لدراسة التجارب المختلفة

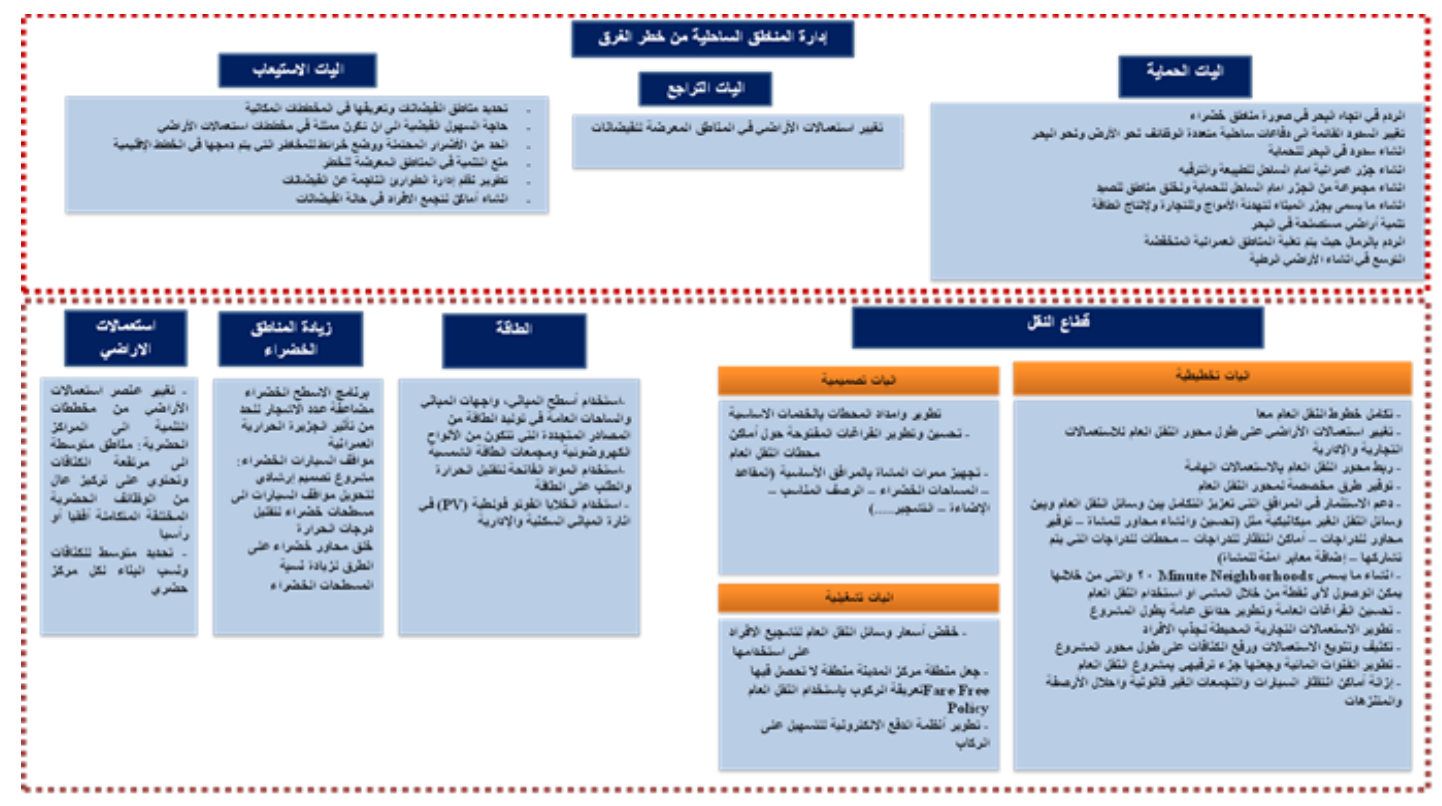


5- الإطار المبئي المقترح للتعامل مع ظاهرة زيادة انبعاثات غازات الدفئة في الحالة

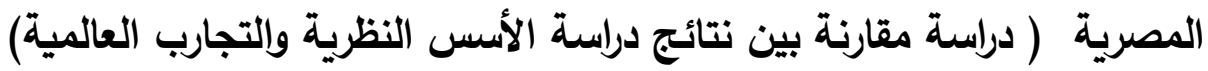

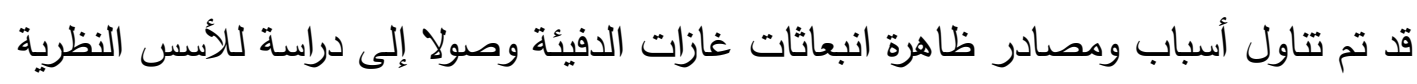
والتجارب العالمية في محاولة للوصول إلى آليات للتعامل مع هذه الظاهرة والحد من تأثيراتها

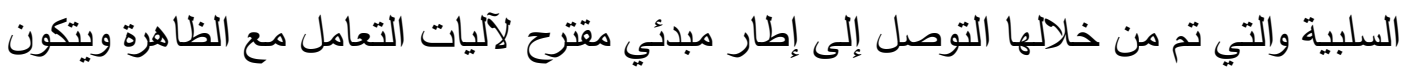

جدول (4): الإطار المبدئي المقترح للتعامل مع ظاهرة زيادة انبعاثات غازات الدفيئة في الحالة المصرية

\begin{tabular}{|c|c|}
\hline \multicolumn{2}{|l|}{ 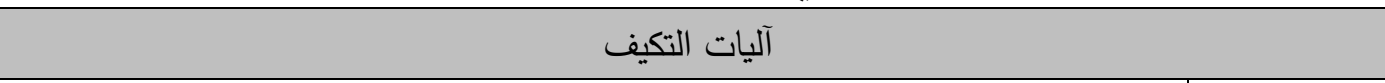 } \\
\hline إنثاء الهياكل الصلبة مثل السدود، حواجز الدد والجزر وكاسرات الأمواج & \multirow{7}{*}{ 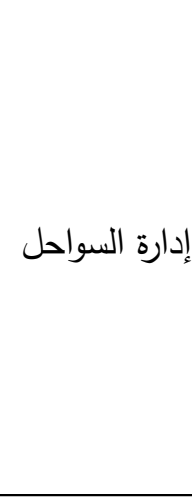 } \\
\hline إنثاء الهياكل الخفيفة مثل الكثبان الرملية وتغذية الثواطئ & \\
\hline استعادة الأراضي الرطبة & \\
\hline نظم الإنذار المبكر والإخلاء & \\
\hline تغيير السدود القائمة إلى دفاعات ساحلية متعددة الوظائف نحو الأرض ونحو البحر & \\
\hline إنشاء مجموعة من الجزر أمام الساحل للحماية ولخلق مناطق للصيد & \\
\hline تتمية أراضي مستصلحة في البحر & \\
\hline \multicolumn{2}{|l|}{ آليات التخفيف } \\
\hline تشجيع وتعزيز استخدام النقل العام & \multirow[b]{4}{*}{ 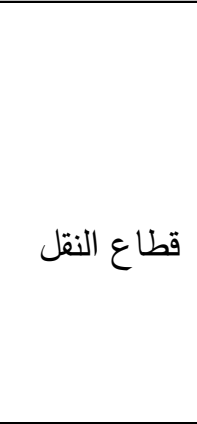 } \\
\hline توفير حارات أو طرق مخصصة لمحور النقل العام & \\
\hline تحسين وتعزيز المشي وركوب الدراجات & \\
\hline 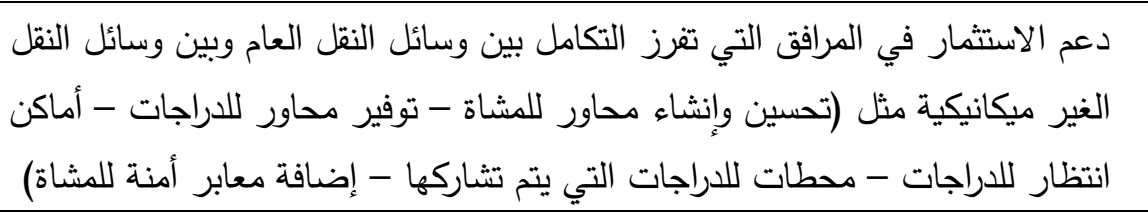 & \\
\hline تعظيم استخدام الطاقة المتجددة (الرياح - الشمس ..................). & \multirow{2}{*}{ قطاع الطاقة } \\
\hline Photovoltaic Systems التخطيط لأنظمة الخلايا الكهروضوئية & \\
\hline تثجيع استعمالات الأراضي الدختلطة لتقليل مسافة الرحلات & \multirow{7}{*}{ الأتعمالات } \\
\hline تحديد متوسط للكثافات ونسب البناء لكل منطقة سكنية & \\
\hline رزاعة الأسطح & \\
\hline "زيادة زراعة الأشجار على طول الطرق للتقليل من تأثير ظاهرة الجزيرة الحرارية & \\
\hline زيادة المسطحات والخضراء لتقليل معدلات الانبعاثات الملوثة وتحسين جودة الهواء & \\
\hline مسطحات خضراء السيارات الخضراء : مشروع تصميم إرشادي لتحويل مواقف السيارات إلى & \\
\hline Urban agricultural & \\
\hline
\end{tabular}




\section{5-5 التكيف مع غرق المناطق الساحلية نتيجة ارتفاع منسوب سطح البحر}

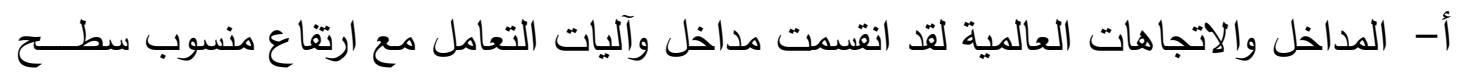

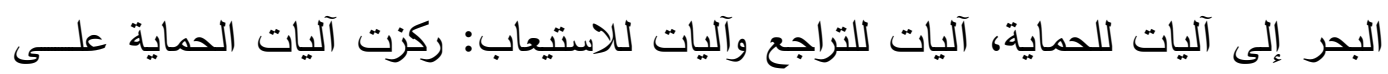

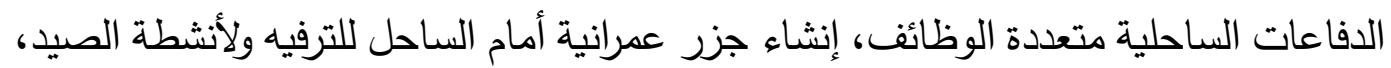

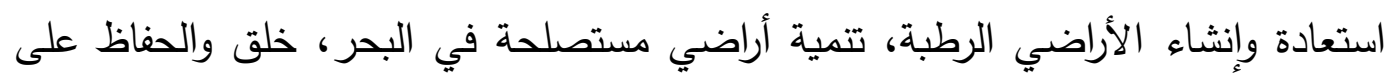

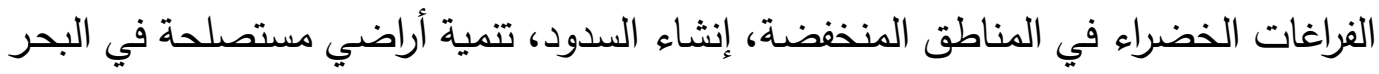

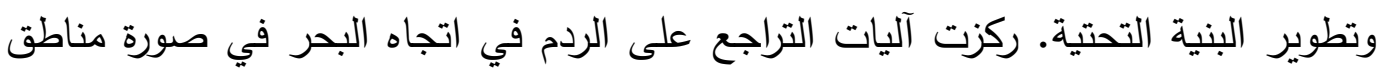

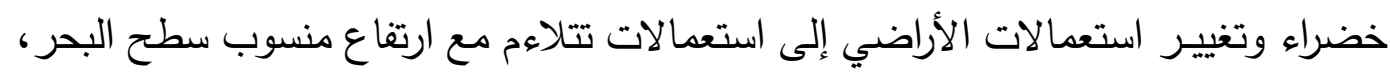

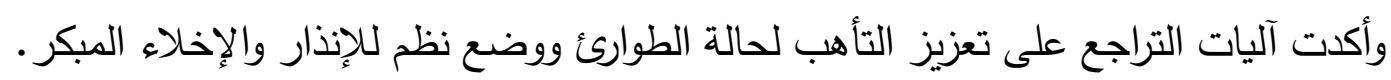

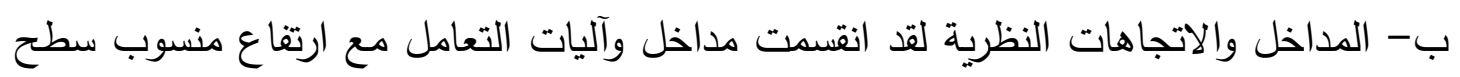

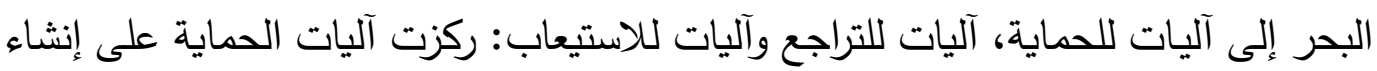

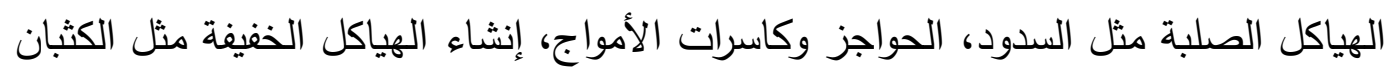
الرملية واستعادة الأراضي الرطبة. ركزت آليات التراجع على إنثاء مناطق لتجمع الأفراد

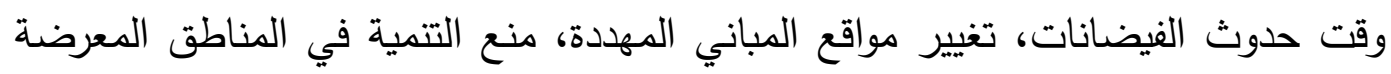

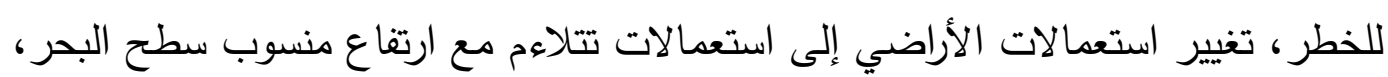

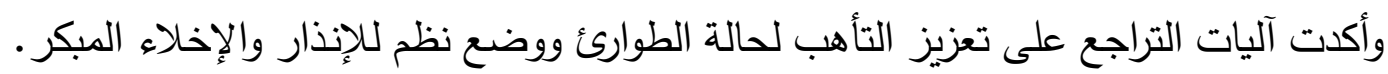
2-5 ـ التخفيف من انبعاثات غازات الدفيئة للقطاعات المختلفة التئة

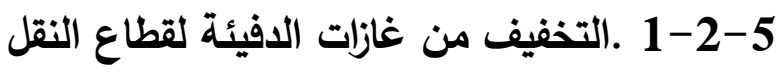
أكدت الأسس النظرية والتجارب العالمية على ضرورة تثجيع النقل العام وتعزيز حركة المشاة لـ الحد من الظاهرة.

2-2-5. التخفيف من غازات الدفيئة لقطاعات الطاقة، استعمالات الأراضي

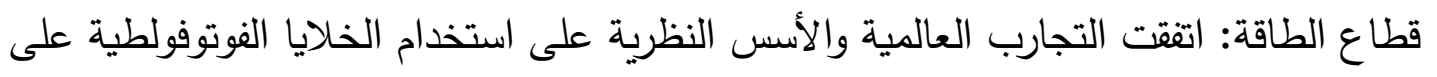
أسطح وواجهات المباني لتوليد الطاقة الكهربائية من مصادر الطاقة المتجددة والحد من استهلاكي

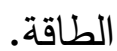

قطاع المناطق الخضراء: تم التأكيد في كلا من الأسس والتجارب على خلق شبكة مترابطـــــة

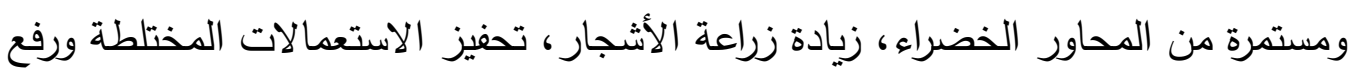
متوسط الكثافات ونسب البناء. وقد تم الوصول للإطار المبئي المقترح للتعامل مع ظاهرة زيادة انبعاثات غازات الدفيئة في الحالــة المصرية كما يوضحها الجدول (4). 
6- اختبار الإطار المبئي المقترح للتعامل مع ظاهرة زيادة انبعاثات غازات الدفيئة في الحالة

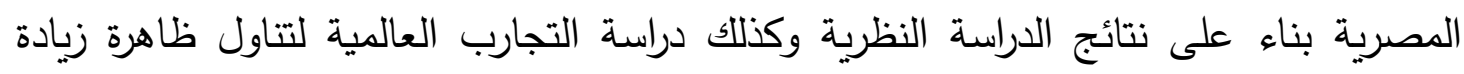

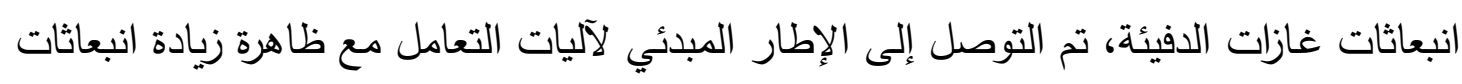

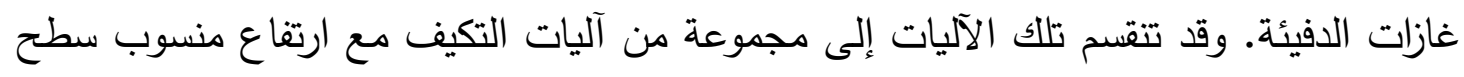

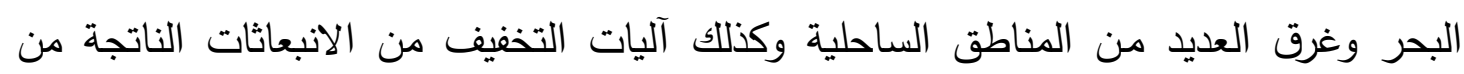
قطاعات النقل، الطاقة واستعمالات الأراضي. وقد جاءت الحاجة إلى اختبار تلك الآليات من خلال إجراء مجموعة من اللقاءات التهات والمقابلات مع

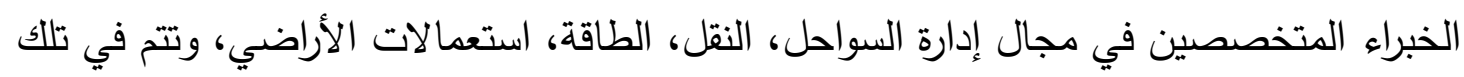

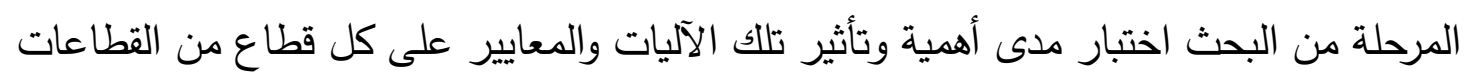

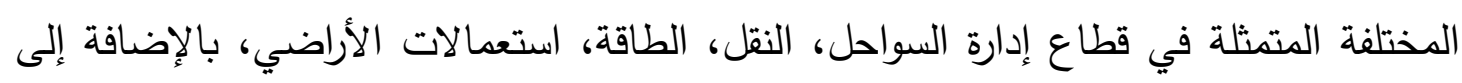

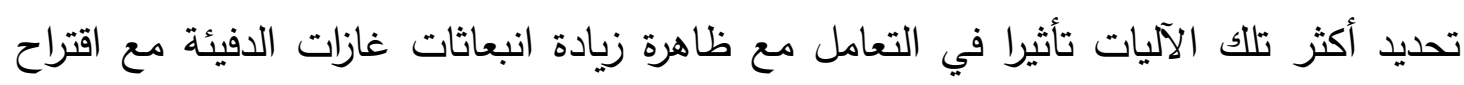

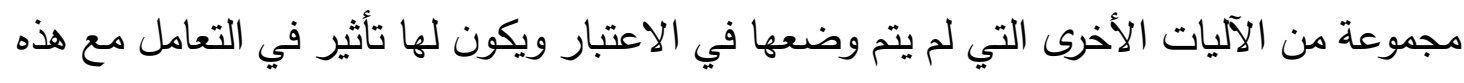
الظاهرة وذلك كما هو موضح في استمارة الاستبيان المرفقة ملحق رقم (1). شكل (11): العناصر الأكثر تأثيرا من وجهة نظر الخبراء للتعامل مع ظاهرة زيادة انبعاثات غازات الافيئة لقطاع إدارة السواحل

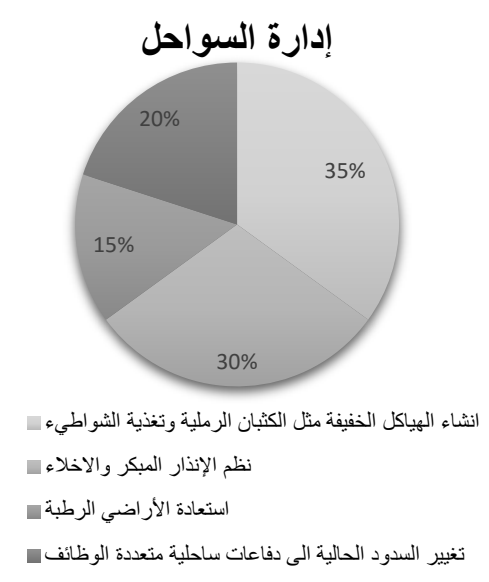

وكل ما سبق في محاولة للوصول إلى الإطار النهائي المقترح لآليات التعامل مع زيادة انبعاثات

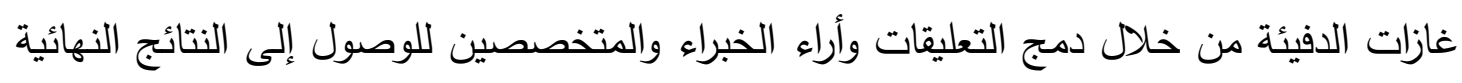
للبحث.

سنستعرض تالياً النتائج النهائية للبحث من خلال دمج التعليقات وآراء الخبراء والمتخصصين.

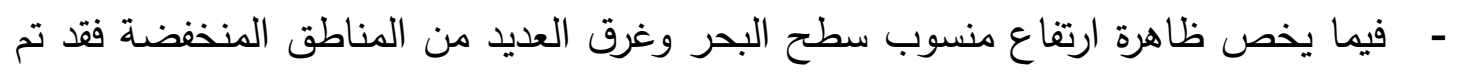

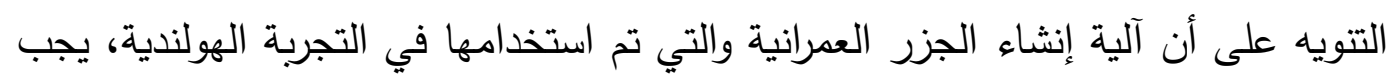


أن تراعي أن طبيعة بحر الثمال تختلف عن البحر المتوسط حيث أن المياه ضحلة ودرجة الميل منخفضة مما يسمح بإنشاء جزر أمام الساحل باستخدام الردم، لكن البحر المتوسط لئل

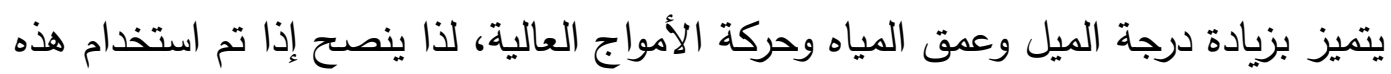
الآلية أن يتم إنشاء هذه الجزر من الخرسانة مع دراسة آثار هذه الجزر على الكائنات الحية.

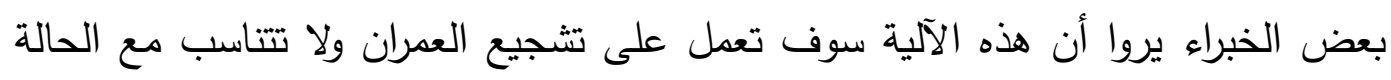

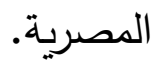
- عدم وجود إطار قانوني أو تشريعي لتتظيم أعمال المناطق المعرضة للخطر حيث يحتاج الأمر إلى تعديل القوانين الحالية ودمجها في قانون واحد لحمبئ لحماية الثواطئ.

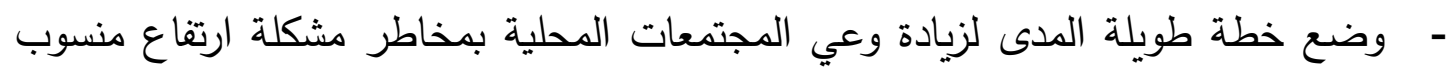

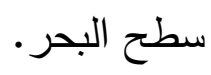
شكل (12): العناصر الأكثر تأثيرا من وجهة نظر الخبراء للتعامل مع ظاهرة زيادة انبعاثات غازات الافيئة لقطاع النقل

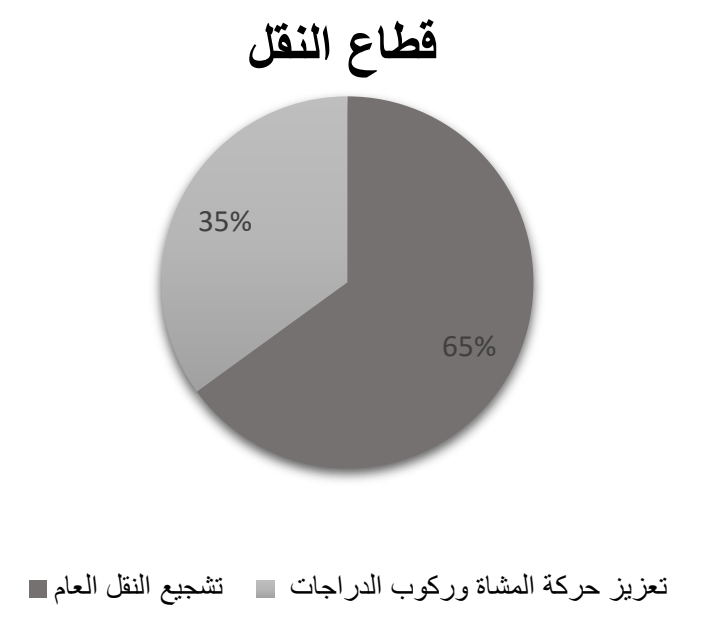

- أحد الخبراء كان يرى أن يتم التركيز على آليات التخفيف من انبعاثات غازات الدفيئة وعـدم

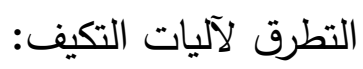
- مع مشكلة ارتفاع منسوب سطح البحر وتهديد السواحل، لان الموضوع يحتاج إلى دراسة أكبر وأكثر تحليلا. 
شكل (13): العناصر الأكثر تأثيرا من وجهة نظر الخبراء للتعامل مع ظاهرة

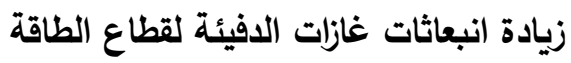

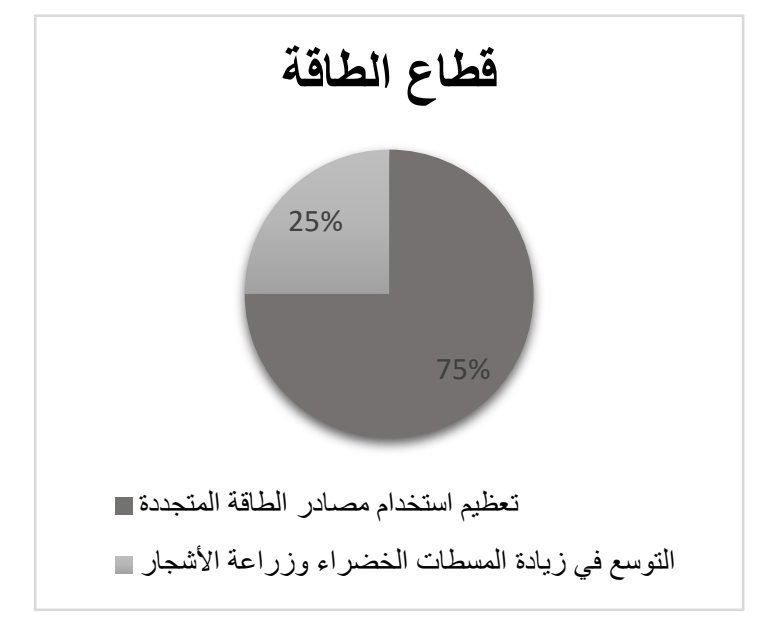

- تحتاج كل الآليات المقترحة لقطاع إدارة السواحل إلى عمل نماذج طبيعية أو رقمية للتأكد من جدواها واختبار تأثيرها لأنها لو لم تتفذ بطريقة علمية صحيحة يمكن أن يكون لها مردود. - ق قطاع النقل تم الاتفاق من قبل الخبراء على ضرورة تشجيع النقل العام كوسيلة رئيسية بدلا من الوسائل الأخرى. - من

- ضرورة التفكير في النقل النهري كوسيلة نقل نظيفة وآمنة. قطاع الطاقة تم التأكيد من قبل الخبراء على أهمية استخدام: - مصادر الطاقة المتجدة والتخطيط لاستخدام الخلايا الكهروضوئية على أسطح وواجهات المباني والساحات العامة لتوليد الطاقة من المصادر المتجددة. - التأكيد على استخدام الطاقة الخضراء من زيادة المسطحات الخضراء والتوسع في زراعة الأشجار والتفكير في زراعة واجهات المباني لما له الأثر في التخفيف من درجات الحرارة وبالتالي تقليل استهلاك الطاقة المستخدمة في أجهزة التبريد. - قطاع استعمالات الأراضي: تم الاتفاق والتأكيد على ضرورة التوسع في زراعة الأشجار لما لها من مردود في التكيف مع ارتفاع درجات الحرارة نتيجة عملية البخر والتقليل من ظاهرة الجزيرة الحراريــة العمرانية، كما أنها تعمل على التخفيف من انبعاثات غازات الدفيئة. 
شكل (14): العناصر الأكثر تأثيرا من وجهة نظر الخبراء للتعامل مع ظاهرة زيادة انبعاثات غازات الافيئة

لقطاع استعمالات الأراضي

قطاع استعمالات الأراضي

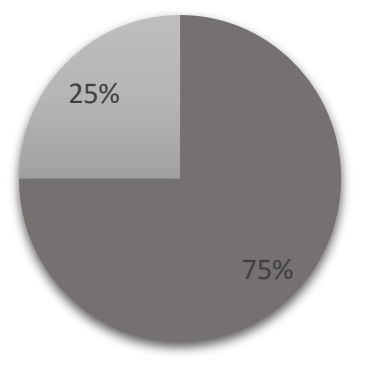

ص الزراعة العمرانية وزيادة اعداد الأشجار

| اتثجيع استعمالات الأراضي المختلطة

7- الإطار النهائي لصياغة آليات التعامل مع ظاهرة زيادة انبعاثات غازات الدفيئة بالتطبيق على الحالة المصرية. تتمثل أهمية الغازات الدفيئة في كونها مصدر الحياة على سطح الأرض فبدونها لانخفضت درجات الحرارة إلى 30-درجة سيلزيوس وأصبح كوكب الأرض مكان لا نستطيع العيش عليه، إذن فالغـازات الدفيئة هامة لكن تتمثل المشكلة في زيادة تركيز هذه الغازات فزيادة التركيز ينتج عنه ارتفاع درجات الحرارة عن معدلاتها الطبيعية مسببة الكثير من التأثيرات العمرانية، الاقتصادية والبيئية. ترجـح اغلــب الدراسات أن زيادة انبعاثات غازات الدفيئة ناتج عن الأنشطة البشرية المكونة للبيئة العمرانية فـي المــدن. بعد ما تم اختبار الإطار المبئي المقترح للتعامل مع ظاهرة زيادة انبعاثـات غـــازات الدفيئة في الحالة المصريـة والتطرق لتعليقات وآراء الخبراء والمتخصصين تم الوصول إلى الإطـار النهائي لآليات التعامل مع ظاهرة زيادة انبعاثات غازات الدفيئة في الحالة المصرية كما هو موضتح بالجدول التالي. 
جدول (5): الإطار النهائي المقترح لآليات التعامل مع ظاهرة زيادة انبعاثات غازات الدفيئة في الحالة المصرية

\begin{tabular}{|c|c|c|}
\hline \multicolumn{2}{|r|}{ آليات التعامل مع ظاهرة زيادة انبعاثات غازات الدفيئة في الحلة المصرية } & يات \\
\hline \multicolumn{3}{|c|}{ آليات التكيف (للتعامل مع الآثار السلبية الناتجة عن زيادة انبعاثات غازات الافيئة) } \\
\hline$\% 35$ & إنثاء الهياكل الخفيفة مثل الكثبان الرملية وتغذية الثواطئ & \multirow{7}{*}{ السواحل } \\
\hline$\% 30$ & نظم الإنذار المبكر والإخلاء & \\
\hline$\% 20$ & استعادة الأراضي الرطبة & \\
\hline \multirow[t]{4}{*}{$\% 15$} & البحير السدود القائمة إلى دفاعات ساحلية متعددة الوظائف نحو الأرض ونحو & \\
\hline & 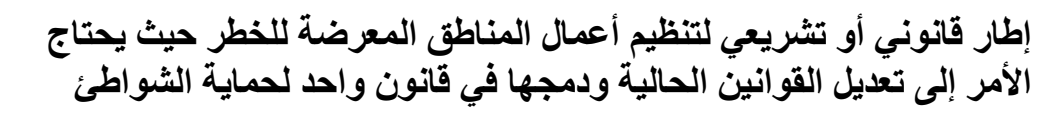 & \\
\hline & وضنفع خطة طويلة المدى لزيادة وعي المجتمعات المحلية بمخاطر مشكلة & \\
\hline & إنشاء الهياكل الصلبة مثل السدود، حواجز المد والجزر وكاسرات الأمواج & \\
\hline \multicolumn{3}{|c|}{ آليات التخفيف للحد من والتخفيف من انبعاثات غازات الدفيئة } \\
\hline$\% 65$ & تشجيع وتعزيز استخدام النقل العام ت & \multirow{4}{*}{ ق ق النقل } \\
\hline \multirow[t]{3}{*}{$\% 35$} & تحسين وتعزيز المشي وركوب الدراجات & \\
\hline & 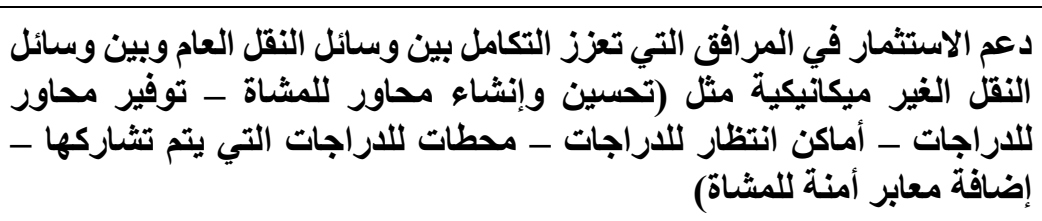 & \\
\hline & توفير حارات أو طرق مخصصة لمحور النقل العام & \\
\hline$\% 100$ & 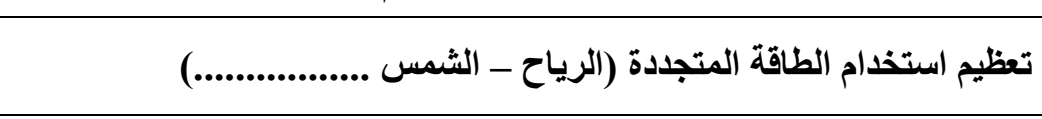 & قاطقة \\
\hline$\% 75$ & الحرارية وزيادة زالمسطحات الخضى طول الطرق للتقليل من تأثير ظاهرة الجزيرة & \multirow{5}{*}{ الأرتعـــالات } \\
\hline \multirow[t]{4}{*}{$\% 25$} & تثجيع استعمالات الأراضي المختلطة لتقليل مسافة الرحلات & \\
\hline & تحليا متوسط للكثافات ونسب البناء لكل منطقة سكنية & \\
\hline & Roof top farm & \\
\hline & مواقف السيارات الخضر اءعراء: مشروع تصميم إرشادي لتحويل مواقف السيارات & \\
\hline
\end{tabular}




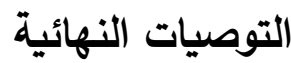

بناء على نتائج البحث التي تم التوصل إليها من خلال الدراسة النظرية والتحليلية والميدانية اتضح أن للتعامل مع ظاهرة زيادة انبعاثات غازات الدفيئة يجب التركيز على القطاعات المسببة للمشكلة متمثلة في قطاعات الطاقة، النقل واستعمالات الأراضي حيث إنها أكثر القطاعات مسببة لزئية لزيادة انبعاثات غازات الدفيئة في مصر ولذللك للتخفيف من انبعاثات هذه القطاعات يجب التبات التركيز في

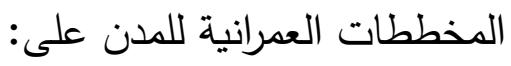

- توجيه سياسات الدولة لدعم مشروعات النقل العام وتقليل الاعتماد على السيارات. - - تكامل بين رؤى المخططات العمرانية للمدن وبين مخططات النقل العام وتحقيق التكامل بينهم. - يجب وضع خطط للطاقة المتجددة على المستوى العمراني أو الإقليمي ولابد أن يتم اتخاذ وصول الطاقة الثمسية solar Access بعين الاعتبار ضمن المراحل الأولى للتخطيط والتأكيد على أن غالبية المباني تأخذ التوجيه بين الجنوب الشرقي والجنوب الغربي للحصول التصني على درجة وصول للطاقة الشمسية جيدة. - - التخطيط الفعال ووضع سياسات لاستعمالات الأراضي لتقليل مسافات السفر .

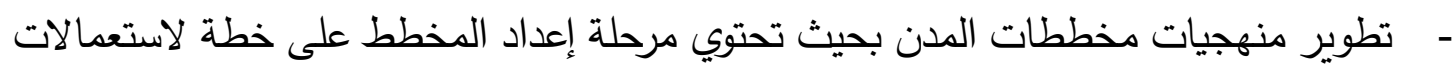

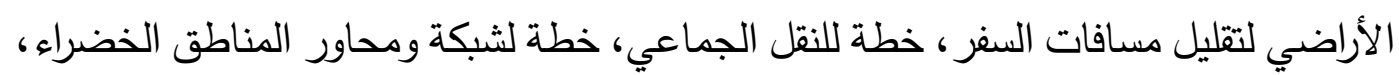
خطة للطاقة الجديدة والمتجددة وخطة لإدارة المخلفات الصلبة.

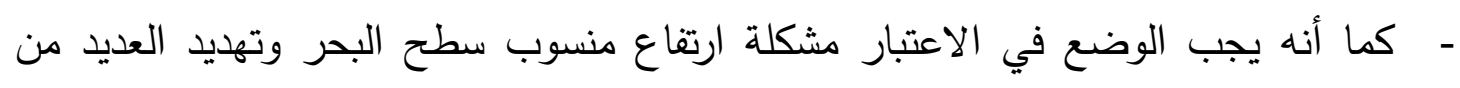

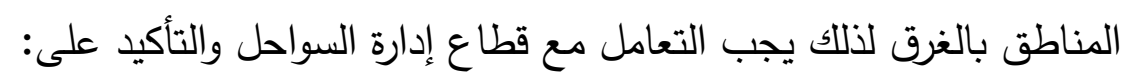

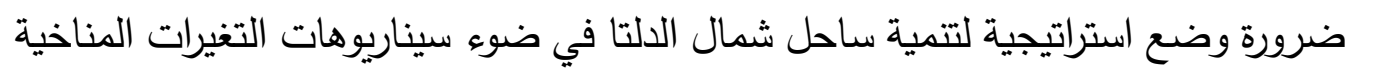

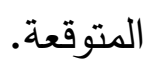
•صياغة مخطط لإدارة المناطق الساحلية مع وجود إطار مؤسسي واضح للإدارة المتكاملة لل للمناطق الساحلية. تعديل التشريعات والقوانين لتراعي مخاطر التغيرات المناخية وتأكل الشواطئ.

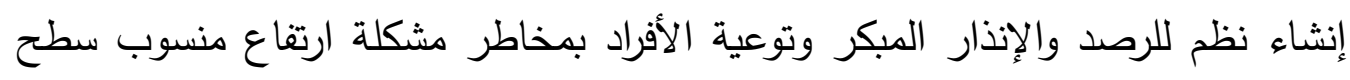




\title{
المراجع
}

\section{أولاً: المراجع باللغة العربية}

\author{
IPCC. التقرير الرابع للهيئة الحكومية الدولية المعنية بتغير المناخ(2007) - \\ - التقرير السنوى لوزارة البيئة .وزارة البيئة(2014) -

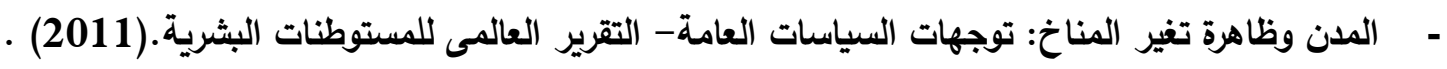

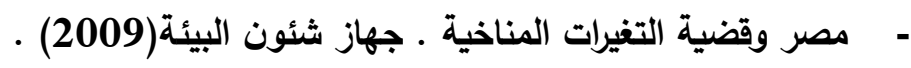

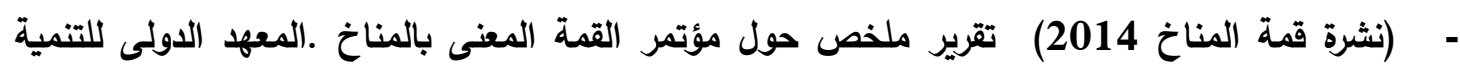 \\ المستدامة بالتعاون مع المكتب التنفيذى للامين العام للامم المتحدة.

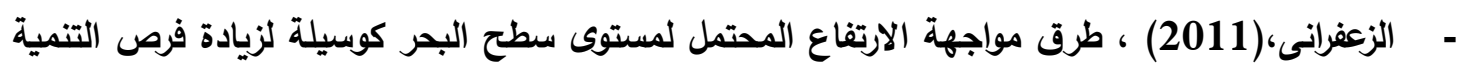

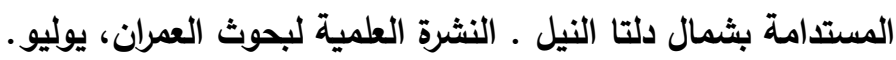 \\ - عاصم عبد السلام محمد 2009، تعظيم شبكة المناطق الخضراء لمدينة القاهرة، (دراسة غير منشورة)، \\ ماجستير ، جامعة القاهرة.
}

\section{ثانياً: المراجع باللغة الأجنبية}

- A. Behfar, M. M. (2013). Optimizing energy performance of a neighborhood via IMM® methodology: Case Study of Barcelona. NTERNATIONAL JOURNAL of ENERGY and ENVIRONMENT.

- Axel Baeumler, E. I.-V. (2012). Sustainable Low-Carbon City Development in China. The World Bank.

- Bergama, C. (2016). Every other plant being built is powered by renewable energy. 2015 has been a good year. Retrieved from http://www.lifegate.com.

- C. Giannakopoulos, M. B. (2005). Climate change impacts in the Mediterranean resulting from a $20 \mathrm{C}$ global temperature rise. Gland, Switzerland: WWF.

- Carter, A. K. (2010). Adaptation to climate change using green and blue infrastructure. University of Manchester.

- Casper, J. K. (2010). Greenhouse Gases: Worldwide Impacts. Infobase publishing.

- (2010). CITIES AND CLIMATE CHANGE: AN URGENT AGENDA- The International Bank for Reconstruction and Development/ The World Bank .

- (2010) .Verifying Greenhouse Gas Emissions:: Methods to Support International Climate Agreements .National Academies Press

- (2010). Egypt National Environmental, Economic and Development Study (NEEDS) for Climate Change under the United Nations Framework Convention on Climate Change. Egyptian Environment Affairs Agency.

- (n.d.). PROMOTING MIXED-USE DEVELOPMENT.

- Donna Munro .(2008) .Planning for Urban Scale Photovoltaic Systems.

- Eldeberky, Y. (2011). Coastal adaptation to sea level rise along the Nile delta, Egypt. Transactions on Ecology and the Environment,Vol 149.

- El-Din, M. M. (2013). Proposed Climate Change Adaptation Strategy for the Ministry of Water Resources \& Irrigation in Egypt. Ministry of Water Resources and Irrigation.

- Hiroaki Suzuki, R. C. (2013). TRANSFORMING CITIES WTH TRANSIT: Transit and Land-Use Integration for Sustainable Urban Development. washington: THE WORLD BANK.

- Holdren, J. P. (n.d.). Meeting the Climate-Change Challenge.

- Lehmann, S. (2014). Low Carbon Cities: Transforming Urban Systems. Routledge. 
- Potential Impacts of Climate Change on the Egyptian Economy. Egyptian Environmental Affairs Agency. (2013).

- Mann \& Kump (2015), Dire Predictions: Understanding Climate Change, $2^{\text {nd }}$ Edition Pearson Education, Inc.

- Ng, E. (2010). Designing High-Density Cities for Social and Environmental Sustainability. Earthscan.

- Raey, M. E. (2009). Impact of Climate Change on The Nile Delta Region An Early Warning Analysis.

- Roggema, R. (2009). Adaptation to Climate: A Spatial challenge. springer.

- Ng, E. (2010). Designing High-Density Cities for Social and Environmental Sustainability. Earthscan.

- Tan, Z. (2014). Air Pollution and Greenhouse Gases: From Basic Concepts to Engineering Applications for Air Emission Control. springer.

- $\quad$ Thompson, A. (2015, january 13). 2015 Begins With CO2 above 400 PPM Mark. Retrieved from http://www.livescience.com/49445-2015-begins-with-co2-above-400-ppmmark.html.

- (n.d.). PROMOTING MIXED-USE DEVELOPMENT.

- Seliem, M. (2010). Coastal Protection Works on Nile Delta As Seen on Google Earth (December 2010).

- Shaw, A. I. (2009). Egyptian Compact-City Veracity: The Fallacy and Credibility of Mixed Use and High Density for a Low Carbon City. 45th ISOCARP Congress.

- Simin Davoudi, J. C. (2009). PLANNING FOR CLIMATE CHANGE STRATEGIES FOR MITIGATION AND ADAPTATION FOR SPATIAL PLANNERS. london: Earthscan.

- IEA, 2015. Egypt Energy Balances data. See http://www.iea.org/countries/nonmembercountries/egypt/.

- IEA, 2011. Facts on Egypt. See http://www.iea.org/media/news/facts_egypt.pdf.

- IEA, 2015. Egypt Electricity / Heat data. See http://www.iea.org/countries/nonmembercountries/egypt/.

- UNFCCC, 2014, cited in Grantham Research Institute on Climate Change and the Environment, 2015. The 2015 Global Climate

- UNFCCC. (2006). Technologies for adaptation to climate change.

- World Resources Institute Climate Analysis Indicators Tool (WRI CAIT) 2.0, 2015. 


\section{ملحق (1)}

استمارة مقابلة مع الخبراء والمتخصصين للوصول لآليات التعامل

\section{مع ظاهرة زيادة انبعاثات غازات الدفيئة}

توضح الاستمارة التالية مجموعة الآليات التي تم الوصول إليها نتيجة من دراسة الأسس النظرية

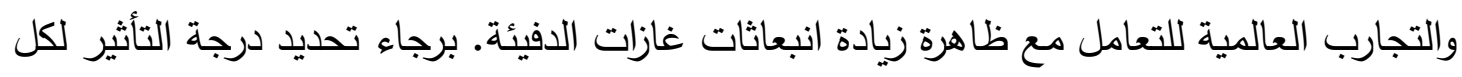

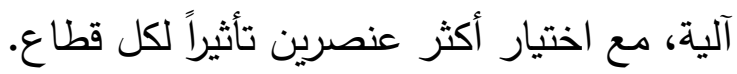

\begin{tabular}{|c|c|c|c|c|c|}
\hline \multicolumn{4}{|c|}{ 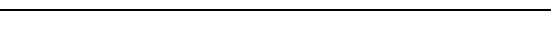 } & \multirow{3}{*}{ 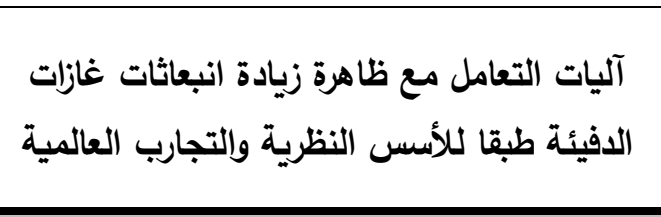 } & \multirow{3}{*}{ القطاعات/آلآ/ات } \\
\hline \multirow{2}{*}{ عنصرين تأثيراً } & \multicolumn{3}{|c|}{ درجة التأثير } & & \\
\hline & قوي & متوسط & ضعيف & & \\
\hline \multicolumn{6}{|c|}{ آليات التكيف (للتعامل مع الآثار السلبية الناتجة عن زيادة انبعاثات غازات الدفيئة) } \\
\hline & & & & • • إنشاء الهياكل الصلبة مثل السدود، حواجز المد & \multirow{9}{*}{ السوارة } \\
\hline & & & & • إنشاء الهياكل الذفيفة مثل الكثبان الرملية وتغذية & \\
\hline & & & & • • استعادة الأراضي الرطبة & \\
\hline & & & & • • نظم الإنذار المبكر والإخلاء & \\
\hline & & & & • ت تغيير السدود القائمة إلى دفاعات ساحلية متعددة & \\
\hline & & & & • • إنشاء مجموعة من الجزر أمام الساحل للحماية & \\
\hline & & & & • ت تمية أراضي مستصلحة في البحر & \\
\hline & & & & $\bullet$ & \\
\hline & & & & 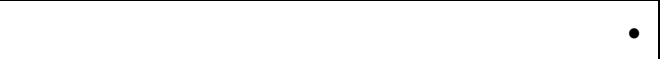 & \\
\hline \multicolumn{6}{|c|}{ آليات التخفيف للحد من والتخفيف من انبعاثات غازات الافيئة) } \\
\hline & & & & • تشجيع وتعزيز استخدام النقل العام & \\
\hline & & & & • توفير حارات أو طرق مخصصة لمحور النقل العام & \\
\hline & & & & • تحسين وتعزيز المشي وركوب الاراجات & قطاع النقل \\
\hline
\end{tabular}




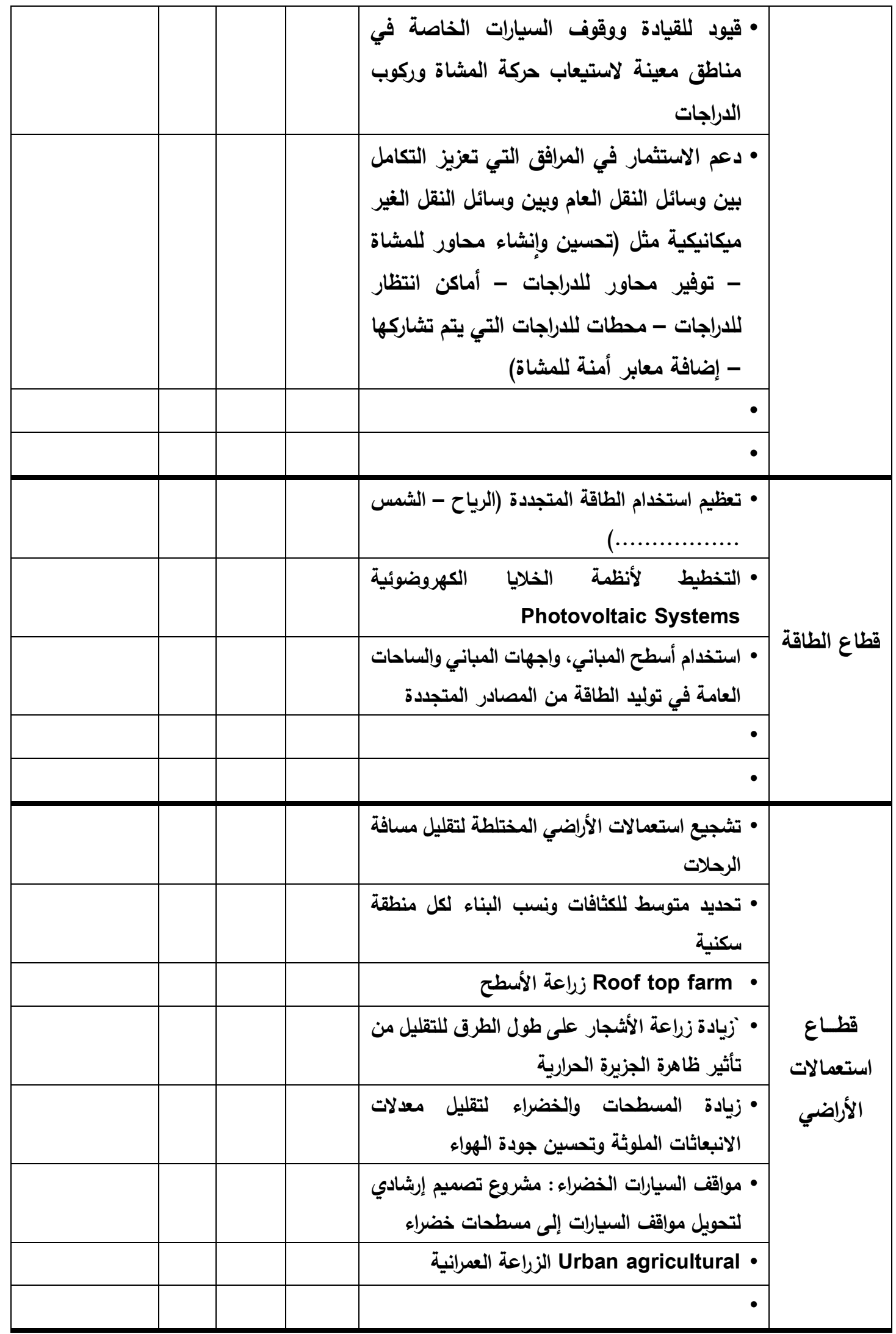

